\title{
Percutaneous mitral balloon valvuloplasty - state of the art
}

\author{
Igor F. Palacios \\ Director of Interventional Cardiology Emeritus, Division of Cardiology, Department of Medicine, Massachusetts General \\ Hospital, Harvard Medical School, Boston, MA 01890, USA.
}

Correspondence to: Prof. Igor F. Palacios, Division of Cardiology, Department of Medicine, Massachusetts General Hospital, Harvard Medical School, Boston, MA 01890, USA.E-mail: ipalacios@mgh.harvard.edu

How to cite this article: Palacios IF. Percutaneous mitral balloon valvuloplasty - state of the art. Mini-invasive Surg 2020;4:73. http://dx.doi.org/10.20517/2574-1225.2020.72

Received: 8 Jul 2020 First Decision: 7 Aug 2020 Revised: 13 Aug 2020 Accepted: 18 Aug 2020 Published: 24 Oct 2020

Academic Editor: Azeem Latib Copy Editor: Cai-Hong Wang Production Editor: Jing Yu

\begin{abstract}
Since its introduction in 1982, percutaneous mitral balloon valvuloplasty (PMV) has been used successfully as an alternative to open or closed surgical mitral commissurotomy in the treatment of patients with symptomatic rheumatic mitral stenosis. PMV is safe and effective and provides sustained clinical and hemodynamic improvement in patients with mitral stenosis. The immediate and long-term results appear to be similar to those of surgical mitral commissurotomy. Proper patient selection is an essential step for being able to predict the immediate results of PMV. Candidates for PMV require precise assessment of the mitral valve morphology. The Wilkin's echocardiographic score (Echo-Sc) is currently the most widely used method for predicting PMV outcome. Leaflet mobility, leaflet thickening, valvular calcification, and sub valvular disease are each scored from 1 to 4 . An inverse relationship exists between the Echo-Sc and PMV success. Both immediate and intermediate follow-up studies have shown that patients with Echo-Sc $\leq 8$ have superior results, significantly greater survival, and event free survival compared to patients with Echo-Sc $>8$. We identified other clinical and morphologic predictors of PMV success that include age, pre-PMV mitral valve area, history of previous surgical commissurotomy, and mitral regurgitation (MR), and post-PMV variables (e.g., post-PMV MR $\geq 3+$ and pulmonary artery pressure), that may be used in conjunction with the Echo-Sc to optimally identify candidates for PMV. This concept demonstrates a multifactorial nature of the prediction of immediate and long-term results. Other echocardiographic scores have been developed for the screening of potential candidates for PMV. They include a unique score that take into account the length of the chordae. A novel quantitative score that included the ratio of the commissural areas over the maximal excursion of the leaflets from the annulus in diastole. The components of this score include mitral valve area $\leq 1 \mathrm{~cm}^{2}$, maximum leaflet displacement $\leq 12 \mathrm{~mm}$, commissural area ratio $\geq 1.25$, and sub valvular involvement. Finally, a score that is able to identify patients who are more
\end{abstract}

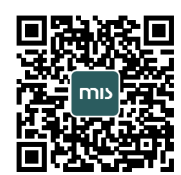


likely to develop significant mitral regurgitation post-PMV. This score takes into account the distribution (even or uneven) of leaflet thickening and calcification, the degree and symmetry of commissural disease, and the severity of subvalvular disease. The transvenous transseptal approach is the most widely used PMV technique. The two major techniques of PMV are the double-balloon technique and the Inoue technique which are equally effective techniques of PMV. Encouraging results of PMV have been reported in special mitral stenosis population cohorts including pregnant women, patients with previous surgical commissurotomy, patients with atrial fibrillation, patients with pulmonary hypertension, elderly patients, patients with calcific mitral stenosis, and patients with associated aortic regurgitation. To summarize, PMV is the preferred form of therapy for relief of mitral stenosis for a selected group of patients with symptomatic mitral stenosis and suitable valve anatomy for valvuloplasty. Patients with Echo-Sc $\leq 8$ have the best results, particularly if they are young, are in normal sinus rhythm, have no pulmonary hypertension, and have no evidence of calcification of the mitral valve under fluoroscopy. The immediate and long-term results of PMV in this group of patients are similar to those reported after surgical mitral commissurotomy. Patients with Echo-Sc $>8$ have only a $50 \%$ chance to obtain a successful hemodynamic result with PMV, and the long-term follow-up results are worse than those from patients with Echo-Sc $\leq 8$. In patients with Echo-Sc $\geq 12$, it is unlikely that PMV could produce good immediate or long-term results and they preferably should undergo mitral valve replacement. However, PMV could be considered in these patients if they are high-risk or unqualified surgical candidates.

Keywords: Mitral stenosis, mitral balloon valvuloplasty, rheumatic mitral stenosis

\section{INTRODUCTION}

Mitral stenosis is more often caused by rheumatic heart disease. Other causes of mitral stenosis include severe calcification of the mitral annulus and congenital defects of the mitral valve ${ }^{[1-3]}$. Until the early 1980s, surgery was the only possible treatment for severe mitral stenosis; then, a new alternative appeared, percutaneous mitral balloon valvuloplasty (PMV). Since its introduction in 1982 by Inoue et al. ${ }^{[4]}$ PMV has been used successfully as an alternative to open or closed surgical mitral commissurotomy for the treatment of patients with symptomatic rheumatic mitral stenosis ${ }^{[4-8]}$. In 1986 , we performed the first percutaneous mitral balloon valvuloplasty in the United States in a 70-year-old man with end-stage mitral stenosis $^{[5]}$. What have we learned about this technique over the subsequent 34 years? In this chapter, I report an analysis of the immediate and long-term results of PMV.

\section{PATIENT SELECTION FOR PMV}

Clinical evaluation of patients with mitral stenosis is the first step of the decision to intervene. Excellent results with PMV are seen in individuals with a crisp opening snap, a Wilkin's echocardiographic score $\leq 8$, and no calcium in the commissures. The existence of an opening snap confirms the mitral valve's mobility and pliability. As the mitral valve becomes severely calcified and immobilized, the opening snap disappears and the first heart sound amplitude decreases. Appropriate patient selection is an essential step when predicting the immediate results of PMV. Candidates for PMV require precise assessment of mitral valve morphology $y^{[7,9-12]}$. The assessment of the anatomy of the mitral valve is critical and it aims to eliminate contraindications and define prognostic considerations. Table 1 shows current American Heart Association/ American College of Cardiology, and European guidelines for the use of PMV ${ }^{[13,14]}$. The presence of a left atrial thrombus is the main contraindication for the technique and requires the performance of transesophageal echocardiography before the procedure [Table 1].

As shown in Tables 2 and 3, PMV is a safe procedure that produces good immediate hemodynamic outcome, low complication rate, and clinical improvement in the majority of patients with mitral stenosis $^{[8,9,15-17]}$. The immediate and long-term results appear to be similar to those of surgical mitral 
Table 1. Recommendations for percutaneous mitral valvuloplasty

\begin{tabular}{|c|c|c|}
\hline Current indication & Class & Level of evidence \\
\hline $\begin{array}{l}\text { Asymptomatic patients with moderate or severe mitral stenosis }\left(\text { area }<1.5 \mathrm{~cm}^{2}\right) \text { and } \\
\text { valve morphology favorable for } \mathrm{PMV} \text { who have pulmonary hypertension }(\mathrm{PA} \text { pressure } \\
\text { systolic }>50 \mathrm{mmHg} \text { at rest or } 60 \mathrm{mmHg} \text { with exercise) in the absence of left atrium } \\
\text { thrombus or moderate to severe } \mathrm{MR}\end{array}$ & I & Grade A \\
\hline $\begin{array}{l}\text { Patients with NYHA functional class II-IV, moderate or severe mitral stenosis (area < } \\
1.5 \mathrm{~cm}^{2} \text { ), a non-pliable calcific valve who are at high risk for surgery in the absence of } \\
\text { left atrium thrombus or moderate to severe MR }\end{array}$ & Ia & Grade C \\
\hline $\begin{array}{l}\text { Asymptomatic patients, moderate or severe mitral stenosis }\left(\operatorname{area}<1.5 \mathrm{~cm}^{2}\right) \text { and valve } \\
\text { morphology favorable for PMV, who has new onset of atrial fibrillation in the absence } \\
\text { of left atrium thrombus, and moderate to severe MR }\end{array}$ & IIa & Grade B \\
\hline $\begin{array}{l}\text { Patients with NYHA functional Class II-IV, moderate to severe mitral stenosis (area }< \\
1.5 \mathrm{~cm}^{2} \text { ), and non-pliable calcified valve who are low risk for surgery }\end{array}$ & IIb & Grade C \\
\hline Patients with mild mitral stenosis & III & Grade C \\
\hline
\end{tabular}

Adapted from current American College of Cardiology/American Heart Association ${ }^{[13]}$ and European ${ }^{[14]}$ guidelines for the management of patients with valvular heart disease. PMV: percutaneous mitral balloon valvuloplasty; MR: mitral regurgitation; NYHA: New York Heart Association Functional Class of Heart Failure

Table 2. Immediate changes in mitral valve area after PMV

\begin{tabular}{|c|c|c|c|c|c|}
\hline Author & Institution & \# Patients & Age & Pre-PMV & Post-PMV \\
\hline Palacios et al. ${ }^{[10]}$ & $\mathrm{MGH}$ & 1,085 & $55 \pm 15$ & $0.9 \pm 0.3$ & $1.9 \pm 0.6$ \\
\hline Lung et al. ${ }^{[22]}$ & Tenon & 1,024 & $45 \pm 15$ & $1.0 \pm 0.2$ & $1.9 \pm 0.3$ \\
\hline Hernandez et al. ${ }^{[17]}$ & Clınico Madrid & 561 & $53 \pm 13$ & $1.0 \pm 0.2$ & $1.8 \pm 0.4$ \\
\hline Stefanadis et al. ${ }^{[35]}$ & Athens University & 438 & $44 \pm 11$ & $1.0 \pm 0.3$ & $2.1 \pm 0.5$ \\
\hline Chen et $a{ }^{\left[{ }^{[11]}\right.}$ & Guangzhou & 4,832 & $37 \pm 12$ & $1.1 \pm 0.3$ & $2.1 \pm 0.2$ \\
\hline Dean et al. ${ }^{[9]}$ & Multicenter & 738 & $54 \pm 12$ & $1.0 \pm 0.4$ & $2.0 \pm 0.2$ \\
\hline Herrmann et al. ${ }^{[18]}$ & Multicenter & 200 & $53 \pm 15$ & $1.0 \pm 0.3$ & $1.8 \pm 0.7$ \\
\hline Feldman et al. ${ }^{[37]}$ & Multicenter & 260 & $53 \pm 15$ & $1.0 \pm 0.3$ & $1.8 \pm 0.6$ \\
\hline Reyes et al. ${ }^{[44]}$ & Fattouma & 463 & $33 \pm 12$ & $1.0 \pm 0.2$ & $2.2 \pm 0.4$ \\
\hline Arora et al. ${ }^{[19]}$ & G.B. Pan & 600 & $27 \pm 8$ & $0.8 \pm 0.2$ & $2.2 \pm 0.4$ \\
\hline Cribier et al. ${ }^{[38,39]}$ & Rouen & 153 & $36 \pm 15$ & $1.0 \pm 0.2$ & $2.2 \pm 0.4$ \\
\hline
\end{tabular}

Modified from Palacios IF. Percutaneous mitral balloon valvuloplasty for patients with rheumatic mitral stenosis ${ }^{[1]}$. MGH: Massachusetts General Hospital; PMV: percutaneous mitral balloon valvuloplasty

Table 3. Complications after PMV

\begin{tabular}{|c|c|c|c|c|c|}
\hline Author & Pts & Mortality & Tamponade & Severe MR & Embolism \\
\hline Palacios et al. ${ }^{[10]}$ & 1,085 & $0.6 \%$ & $0.8 \%$ & $2.7 \%$ & $1.2 \%$ \\
\hline Vahanian et al..$^{[16]}$ & 200 & $0.0 \%$ & $0.3 \%$ & $3.4 \%$ & $0.3 \%$ \\
\hline Lung et al. ${ }^{[22]}$ & 1,024 & $0.4 \%$ & $0.0 \%$ & $4.0 \%$ & $4.0 \%$ \\
\hline Hernandez et $\left.a\right|^{[17]}$ & 561 & $0.4 \%$ & $0.6 \%$ & $4.5 \%$ & \\
\hline Stefanadis et al. ${ }^{[35]}$ & 438 & $0.2 \%$ & $0.0 \%$ & $3.4 \%$ & $0.0 \%$ \\
\hline Chen et $a]_{.}^{[11]}$ & 4,832 & $0.1 \%$ & $0.8 \%$ & $1.4 \%$ & $0.5 \%$ \\
\hline Dean et al. ${ }^{[9]}$ & 738 & $3.0 \%$ & $4.0 \%$ & $3.0 \%$ & $3.0 \%$ \\
\hline Herrmann et al..$^{[18]}$ & 200 & $0.6 \%$ & $1.0 \%$ & $2.4 \%$ & $1.5 \%$ \\
\hline Feldman et al. ${ }^{[37]}$ & 260 & $1.1 \%$ & $0.7 \%$ & $4.0 \%$ & $0.7 \%$ \\
\hline Reyes et al. ${ }^{[4]]}$ & 463 & $0.4 \%$ & $0.7 \%$ & $4.6 \%$ & $2.0 \%$ \\
\hline Arora et al. ${ }^{[19]}$ & 600 & $1.0 \%$ & $1.3 \%$ & $1.0 \%$ & $0.5 \%$ \\
\hline Cribier et al. ${ }^{[38,39]}$ & 153 & $0.0 \%$ & $0.7 \%$ & $1.4 \%$ & $0.7 \%$ \\
\hline
\end{tabular}

Modified from Palacios IF. Percutaneous mitral balloon valvuloplasty for patients with rheumatic mitral stenosis ${ }^{[1]}$. PMV: percutaneous mitral balloon valvuloplasty; MR: mitral regurgitation

commissurotomy ${ }^{[10,11,18-20]}$. Nowadays, PMV is the preferred form of therapy for relief of mitral stenosis for a selected group of patients with symptomatic rheumatic mitral stenosis.

The Wilkin's echocardiographic score (Echo-Sc) is currently the most widely used method for patient selection predicting PMV outcome ${ }^{[7,12]}$ (Figure 1, panels A and B display video loops for low and high Echo 

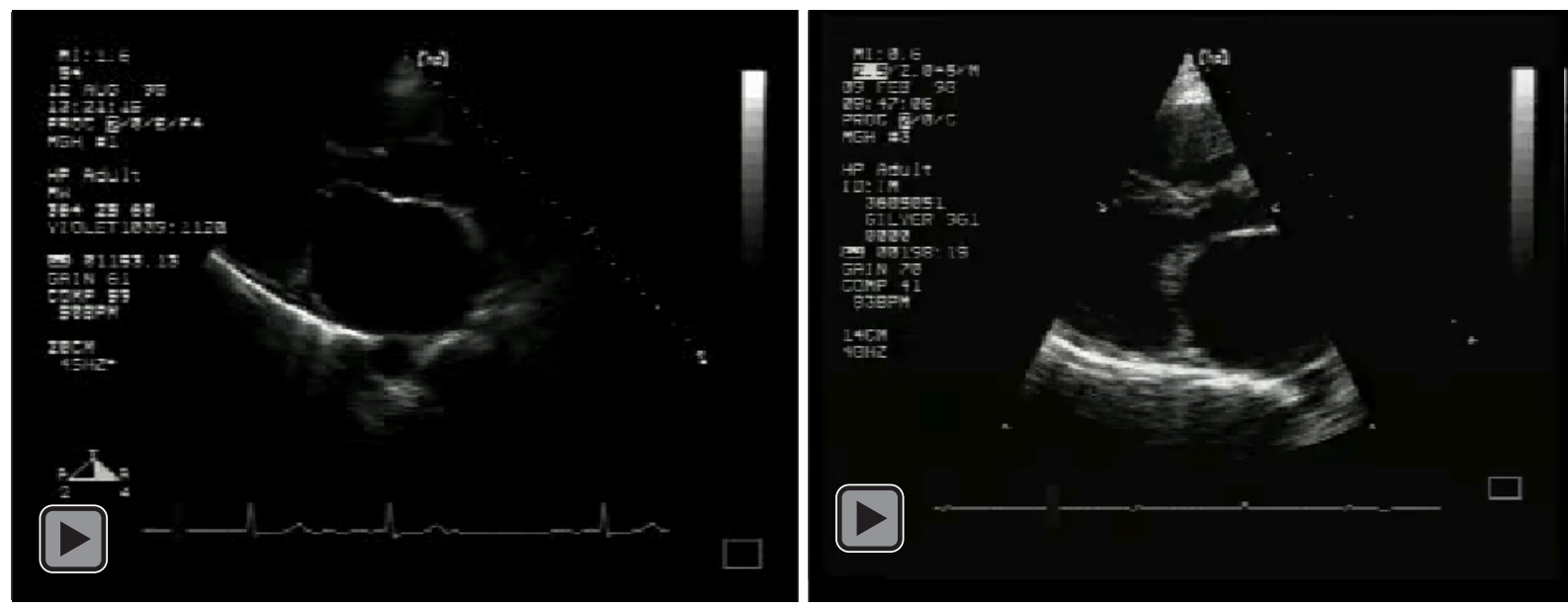

Figure 1. Video loops from a patient with severe mitral stenosis and a low Echo Score of 5 (right panel) and a high Echo Score of 10 (left panel)

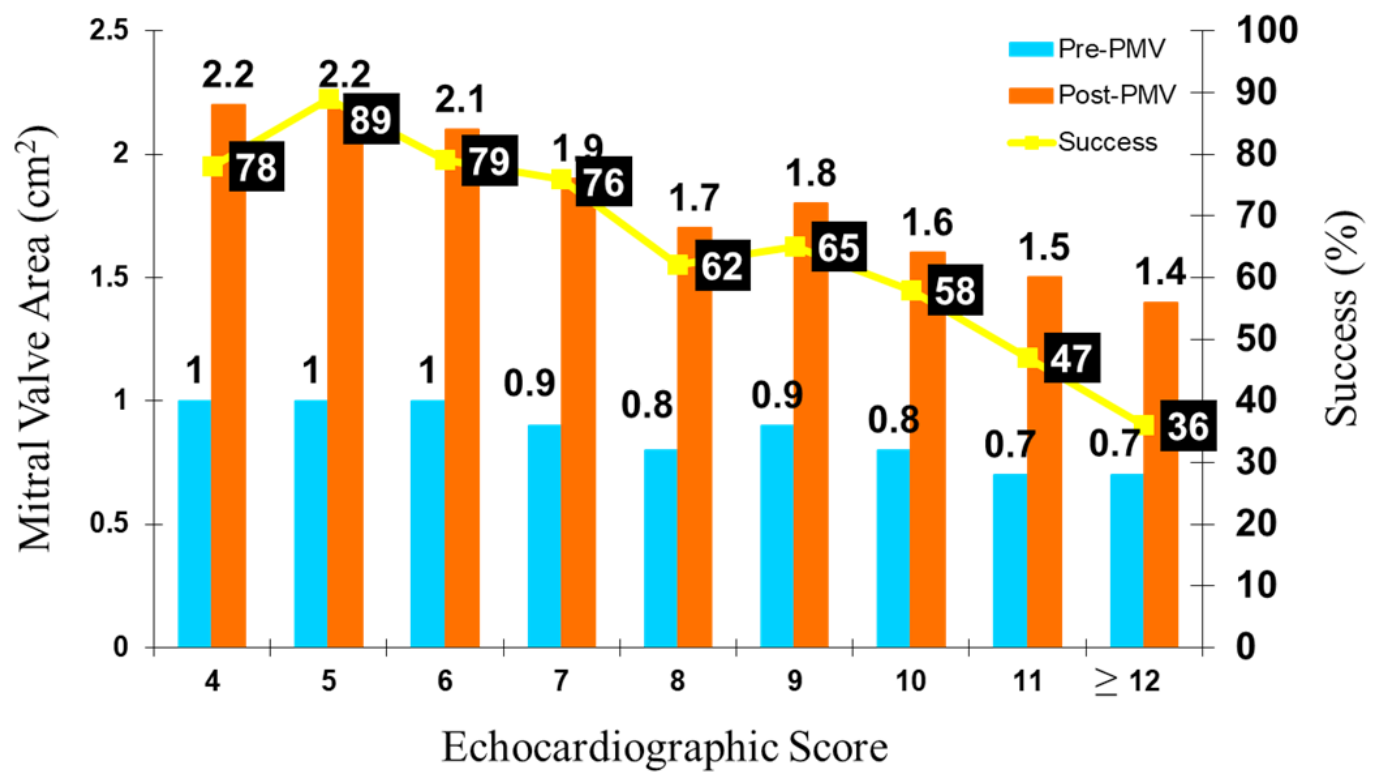

Figure 2. Relationship between the echocardiographic score and changes in mitral valve area after PMV (bar graphs), and relationship between the echocardiographic score and PMV success (line with filled yellow triangles). Numbers at the top of bar graphs represent mean mitral valve areas before (blue bars) and after (orange bars) PMV for each echocardiographic score. Percentages in black squares represent PMV success rate at each echocardiographic score. Modified from Palacios IF, Sanchez PL, Harrell LC, Weyman AE, Block $\mathrm{PC}^{[1,13,18]}$. PMV: percutaneous mitral balloon valvuloplasty

scores, respectively). Leaflet mobility, leaflet thickening, valvular calcification, and sub valvular disease are each scored from 1 to 4, yielding a maximum total Echo-Sc of $16^{[9,12]}$. As shown in Figure 2, an inverse relationship exists between Echo-Sc and PMV success. Both immediate, and intermediate follow-up studies have shown that patients with Echo-Sc $\leq 8$ have superior results and significantly greater survival and combined event free survival than patients with Echo-Sc $>8^{[7,12-14]}$. Long-term follow-up results of PMV are limited ${ }^{[9,10,15-17]}$. Although earlier studies have reported that PMV results in good immediate hemodynamic and clinical improvement in most patients with rheumatic mitral stenosis, superior long-term follow-up results are seen in a selected group of patients with Echo- $S c \leq 8^{[7,8,10,12,15]}$. We have reported that in addition to the Wilkin's Echo-Sc there are other clinical and morphologic predictors of immediate and long-term PMV success. 


\section{Multifactorial Determinants of PMV Procedural Success}

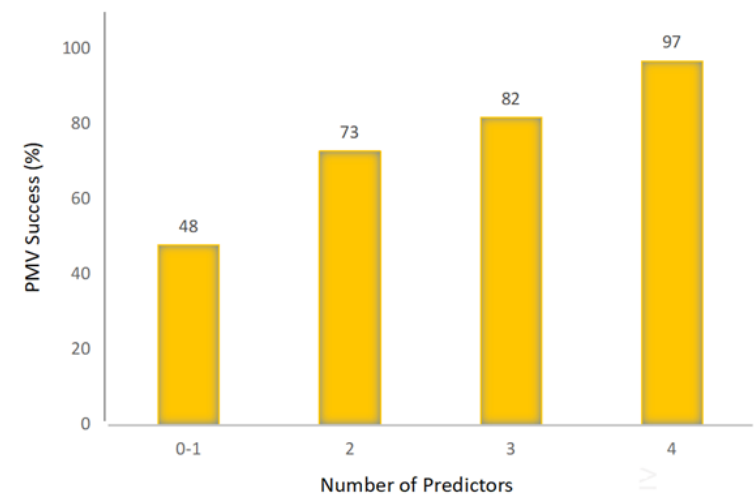

Sanchez M, Cruz, I, Palacios IF, et al. 2006

Figure 3. Multifactorial determinants of immediate and long-term outcomes from PMV. Six independent predictors of PMV success were identified: age less than 55 years, New York Heart Association classes I and II, pre-PMV mitral area of $1 \mathrm{~cm}^{2}$ or greater, pre-PMV mitral regurgitation grade $\leq 2+$, echocardiographic score of $\leq 8$ and male sex. Modified from Cruz-Gonzalez I, Sanchez-Ledesma M, Sanchez PL, Martin-Moreiras J, Jneid H, Rengifo-Moreno P, Inglessis-Azuaje I, Maree AO, Palacios IF ${ }^{[21]}$. PMV: percutaneous mitral balloon valvuloplasty

Cruz-Gonzalez et al. ${ }^{[21]}$ developed a multifactorial score derived from clinical, anatomic, echocardiographic, and hemodynamic variables to predict procedural success and clinical outcome. Six independent predictors of PMV success were identified: age less than 55 years, New York Heart Association classes I and II, pre-PMV mitral valve area of less than $1 \mathrm{~cm}^{2}$, pre-PMV mitral regurgitation Seller's grade $\leq 2+$, echocardiographic score of $\leq 8$, and male sex. A score was constructed from the arithmetic sum of variables present per patient [Figure 3]. Procedural success rates increased incrementally with increasing score (0\% for $0 / 6,39.7 \%$ for $1 / 6,54.4 \%$ for $2 / 6,77.3 \%$ for $3 / 6,85.7 \%$ for $4 / 6,95 \%$ for $5 / 6$, and $100 \%$ for $6 / 6$; $P<0.001$ ). In a validation cohort ( $n=285$ procedures), the multifactorial score remained a significant predictor of PMV success $(P<0.001)$. Comparison between the new score and the Wilkin's Echo-Sc confirmed that the new index was more sensitive and specific $(P<0.001)$. This new score also predicts long-term outcomes $(P<0.001)$. They concluded that clinical, anatomic, and hemodynamic variables predict PMV success and clinical outcome and may be formulated in a scoring system that would help to identify the best candidates for $\mathrm{PMV}^{[21]}$ [Figure 3].

A simpler echocardiographic score for the stenotic mitral valve was introduced by Vahanian et al. ${ }^{[16]}$ and Lung et al. ${ }^{[22]}$. The Cormier score is unique for taking the length of the chordae into consideration. More recently, a novel quantitative score was described by Nunes et al. ${ }^{[23]}$, it included the ratio of the commissural areas over the maximal excursion of the leaflets from the annulus in diastole. Independent predictors of outcome were assigned a point value proportional to their regression coefficients: mitral valve area $\leq 1 \mathrm{~cm}^{2}$, maximum leaflet displacement $\leq 12 \mathrm{~mm}$, commissural area ratio $\geq 1.25$, and sub valvular involvement ${ }^{[24]}$. Three risk groups were defined: low (score of 0-3), intermediate (score of 5), and high (score of 6-11), with observed suboptimal PMV results of $16.9 \%, 56.3 \%$, and $73.8 \%$, respectively. The use of the same scoring system in the validation cohort yielded suboptimal PMV results of $11.8 \%, 72.7 \%$, and $87.5 \%$ in the low-, intermediate-, and high-risk groups, respectively $(P<0.0001)$. Long-term outcome was predicted. The model improved risk classification in comparison with the Wilkins score (net reclassification improvement, $45.2 \% ; P<0.0001)$. Long-term outcome was predicted by age and postprocedural variables, including mitral regurgitation, mean gradient, and pulmonary pressure ${ }^{[23]}$. 
Severe mitral regurgitation after PMV is a major complication of this procedure. This complication confers an adverse prognosis and frequently requires intensive treatment and urgent mitral valve surgery. Although some morphologic features of the mitral valve might increase the risk of severe regurgitation, echocardiographic evaluation with the Wilkin's Echo-Sc has been unable to predict it. Padial et al. ${ }^{[25,26]}$ described a new echocardiographic score that can predict the development of severe mitral regurgitation after PMV with the double balloon and the Inoue balloon techniques. This score takes into account the distribution (even or uneven) of leaflet thickening and calcification, the degree and symmetry of commissural disease, and the severity of sub valvular disease. Thus, echocardiography can identify patients with a high risk of developing severe mitral regurgitation after PMV using this proposed mitral regurgitation echocardiographic score ${ }^{[25-27]}$ This new score can help assess the probability of this complication before the procedure to anticipate the likelihood that surgical repair may be needed. In addition, it could conceivably be used to select patients for modified procedure techniques that might be developed to minimize this complication ${ }^{[25,26]}$. Anwar et al. ${ }^{[28]}$ used a new real-time three-dimensional echocardiography (RT3DE) score for evaluating patients with mitral stenosis (MS) and compared with Echo-Sc. The new RT3DE score was constructed by dividing each mitral valve (MV) leaflet into 3 scallops and was composed of a total of 31 points (indicating increasing abnormality), including 6 points for thickness, 6 for mobility, 10 for calcification, and 9 for subvalvular apparatus involvement. The total RT3DE score was calculated and defined as mild $(<8)$, moderate (8-13), or severe ( $\geq 14)$. Mitral valve morphology was assessed using the Wilkin's Echo-Sc and compared with the new RT3DE score. They reported that the new RT3DE score is feasible and highly reproducible for the assessment of mitral valve morphology in patients with mitral stenosis and it can provide incremental prognostic information in addition to the Wilkin's Echo-Sc ${ }^{[28]}$. However, none of the scores available have been shown to be superior to the others.

\section{COMMISSURAL CALCIFICATIONS AND DEGREE OF COMMISSURAL FUSION AND FEASIBILITY AND EFFICACY OF PMV}

Although echocardiographic scores are important for identifying optimal candidates for PMV, there are other distinctive morphologic features of mitral valve disease whose relationships to outcome after percutaneous mitral valvotomy are also important. Several scores have been developed that take into account the uneven distribution of anatomic abnormalities, in particular in commissural areas ${ }^{[7,25-27,29]}$. Since commissural splitting is the dominant mechanism by which mitral valve stenosis is relieved by this technique, commissural morphology may predict outcome. Figure 4 depicts short axis TTE of one patient with concentric mitral stenosis (right panel) and one patient with eccentric calcification mitral stenosis (left panel). For example, excessive thickening and calcification of one commissure should be expected to decrease the effectiveness of the procedure by limiting the splitting of the involved side of the orifice and predisposing the contralateral commissure to rupture or the normal leaflet to tearing. This could also potentially predispose to severe mitral regurgitation after $\mathrm{PMV}^{[25-27,30]}$. Patients with evidence of calcium in a commissure have a lower survival rate and a higher incidence of mitral valve replacement and all end points combined. Thus, the simple presence or absence of commissural calcification assessed by twodimensional echocardiography can be used to predict outcome $\mathrm{e}^{[25-27,31,32]}$.

\section{TECHNIQUE OF PMV}

The transvenous transseptal approach is the most widely used PMV technique. Transseptal catheterization is the first step of the procedure and one of the most crucial one. The trans-arerial approach could represent an alternative in the rare cases in which the transseptal approach is contraindicated or impossible ${ }^{[33-35]}$. There are currently two main transseptal PMV techniques, balloon valvuloplasty and metallic commissurotomy. The two major techniques of balloon valvuloplasty are the double-balloon technique and the Inoue technique. The double-balloon technique [Figure 5] is effective but demanding and carries the risk of left ventricular perforation by the guidewires or the tip of the balloons ${ }^{[1,5,6,8,10]}$. The 

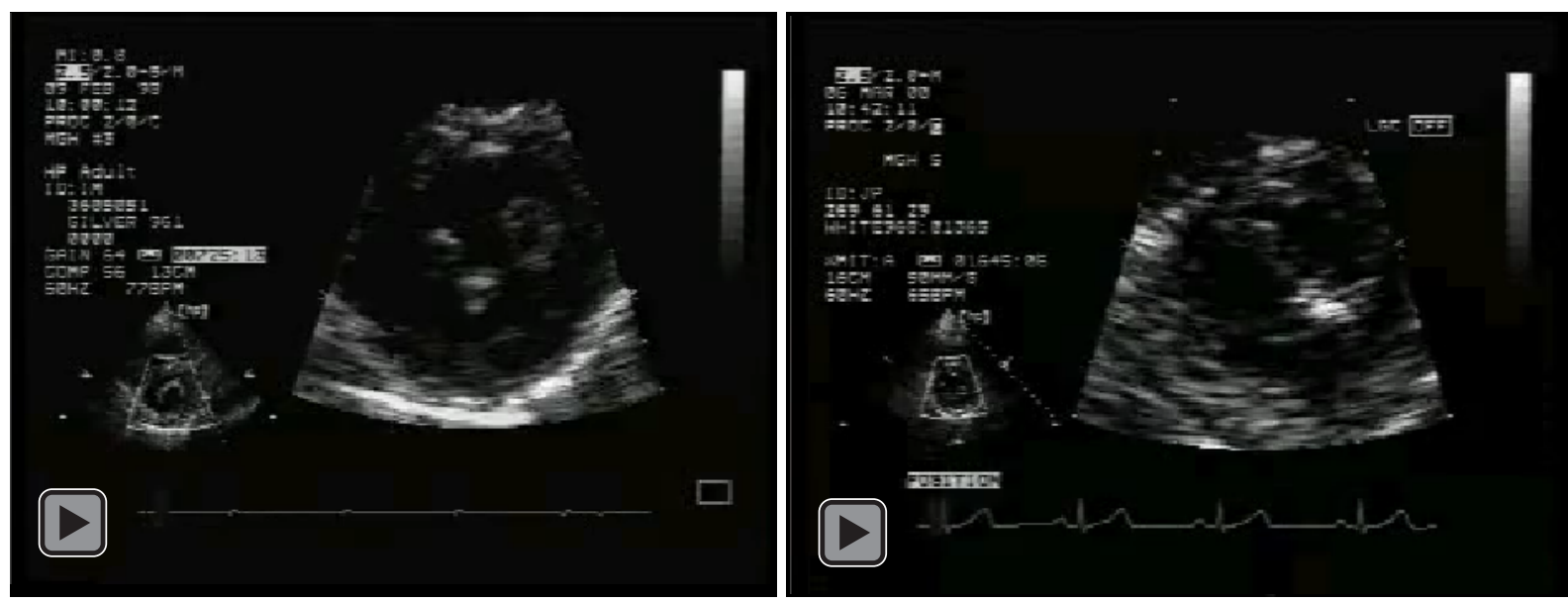

Figure 4. Short axis video loops from a patient with severe mitral stenosis and Concentric MS (right panel) and one patient with Eccentric MS (left panel). MS: mitral stenosis

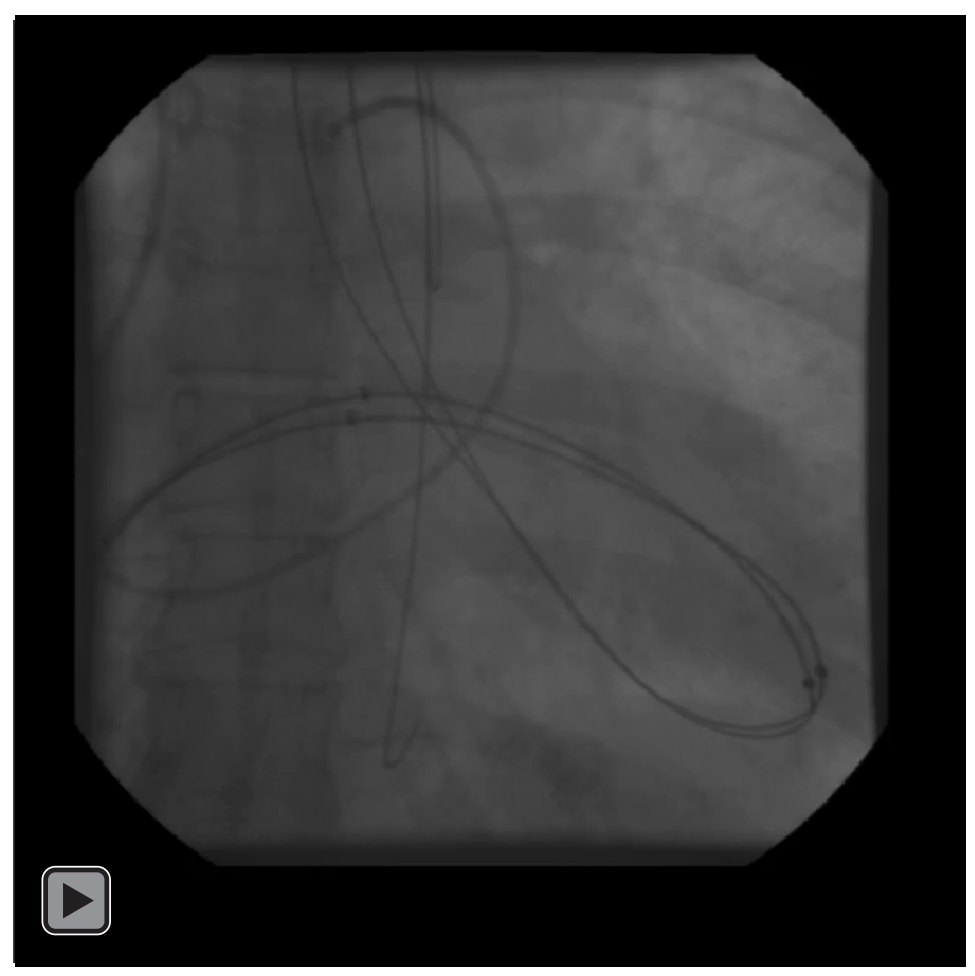

Figure 5. Double balloon mitral valvuloplasty

multi-track system [Figure 6] is a variant of the double-balloon technique and aims to make the procedure easier through the use of a monorail balloon and only a single guidewire ${ }^{[36]}$. The Inoue technique [Figure 7] has become the most popular technique worldwide ${ }^{[4,16,18,22,37]}$. The design of the Inoue balloon allows safe and fast positioning across the valve. In addition, it is pressure extensible, allowing for the performance of a stepwise dilatation [Figure 7]. The available data comparing the Inoue technique and the double-balloon technique suggest that the Inoue technique makes the procedure easier, and that both techniques have equivalent efficacy. Although the double-balloon technique may result in a slightly larger post-PMV valve area, the long-term results are equivalent. Furthermore, the Inoue balloon carries a lower risk because the risk of left ventricular perforation is virtually avoided ${ }^{[16,23,37]}$. 


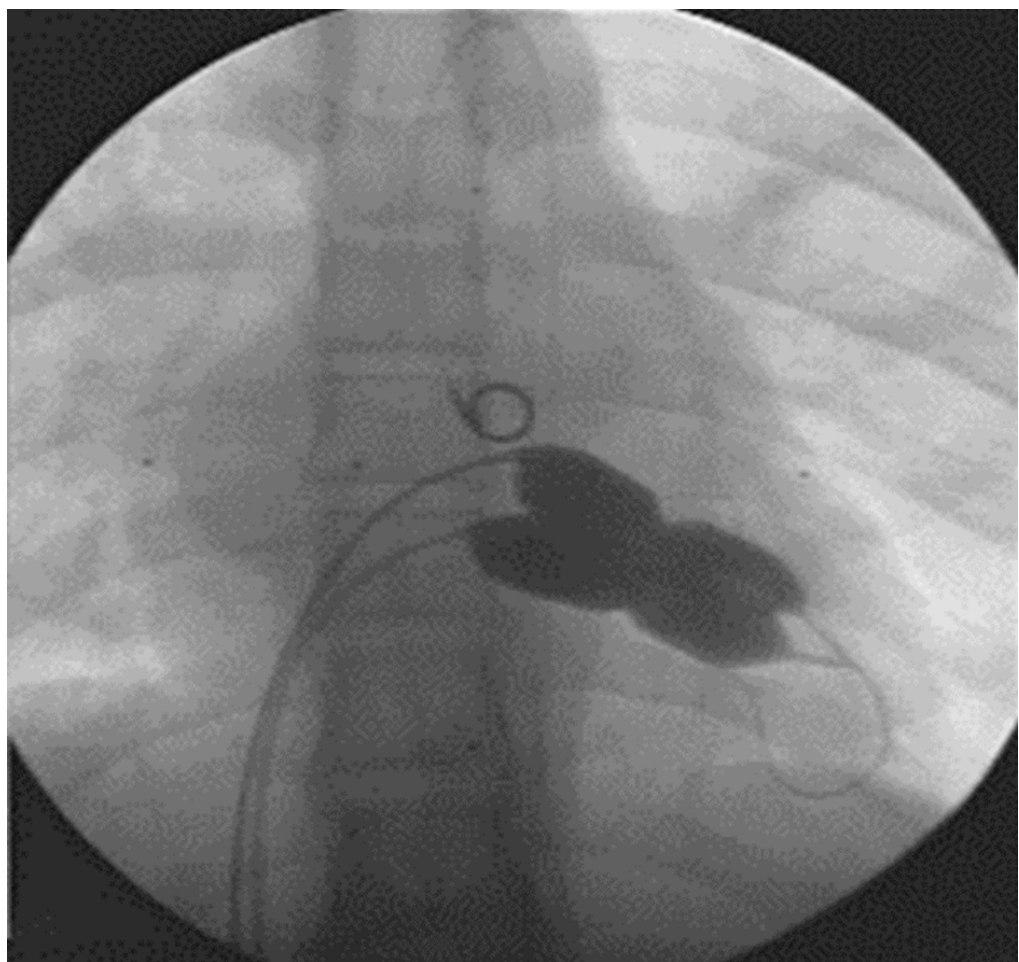

Figure 6. Double balloon percutaneous mitral balloon valvuloplasty using the multitrack balloon catheter

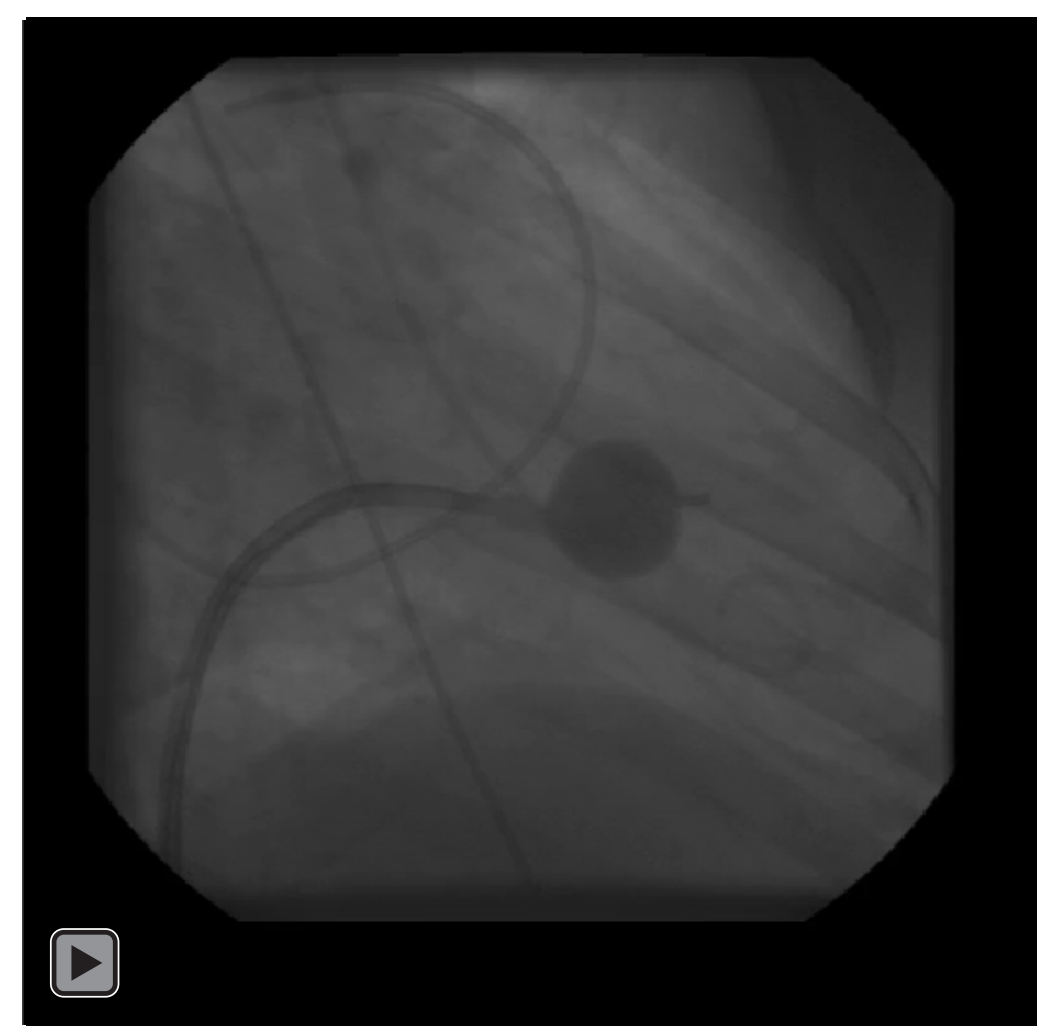

Figure 7. The Inoue balloon technique of percutaneous mitral balloon valvuloplasty 
PMV is performed as previously described ${ }^{[1,2,5,6]}$. All patients should undergo diagnostic right and left, and transseptal left heart catheterization ${ }^{[1,2,5,6]}$. Following transseptal left heart catheterization, systemic anticoagulation is achieved by the intravenous administration of 100 units $/ \mathrm{kg}$ of heparin. In patients older than 40 years, coronary angiography should also be performed. Hemodynamic measurements, cardiac output, and cine left ventriculography are performed before and after PMV. Cardiac output is measured by thermodilution and Fick method techniques. An oxygen diagnostic run is performed after PMV to determine the presence of significant left to right shunt across the interatrial septum after PMV.

\section{THE ANTEGRADE DOUBLE-BALLOON TECHNIQUE}

PMV using the antegrade double-balloon technique [Figure 5] is performed as previously described ${ }^{[1,2,5,6]}$. A $7 \mathrm{~F}$ flow directed balloon catheter is advanced through the transseptal sheath across the mitral valve into the left ventricle $e^{[1,2,5,6]}$. The catheter is then advanced through the aortic valve into the ascending and then the descending aorta. A $0.889 \mathrm{~mm}$ or $0.9652 \mathrm{~mm}, 260 \mathrm{~cm}$ long Teflon coated exchange wire is then passed through the catheter. The sheath and the catheter are removed leaving the wire behind. A $5 \mathrm{~mm}$ balloon dilating catheter occasionally is used to dilate the atrial septum. A second exchange guide wire is pass parallel to the first guide wire through the same femoral vein and atrial septum punctures using a double lumen catheter. The double lumen catheter is then removed leaving the two guide wires across the mitral valve in the ascending and descending aorta. During these maneuvers care should be taken to maintain large and smooth loops of the guide wires in the left ventricular cavity to allow appropriate placement of the dilating balloons. If a second guide wire cannot be placed into the ascending and descending aorta, a $0.9652 \mathrm{~mm}$ Amplatz type transfer guide wire with a preformed curlew at its tip can be placed at the left ventricular apex. In patients with aortic valve prosthesis, two Amplatz type transfer guide wires with preformed curlew tips should be placed at the left ventricular apex. When one or both guide wires are placed in the left ventricular apex, the balloons should be inflated sequentially. Care should be taken to avoid forward movement of the balloons and guide wires to prevent left ventricular perforation. Two balloon dilating catheters, chosen according with the patient's body surface area, are then advanced over each one of the guide wires and positioned across the mitral valve parallel to the longitudinal axis of the left ventricle. The balloon valvuloplasty catheters are then inflated by hand until the indentation produced by the stenotic mitral valve is no longer seen. Generally, one, but occasionally two or three, inflations are performed. After complete deflation, the balloons are removed sequentially. The Multi-track system [Figure 6] introduced by Bonhoeffer, shares the advantages of the traditional double-balloon technique ${ }^{[36]}$. It is safer and reduces the risk of accidental balloon displacement. The procedure is easier to perform as it only requires the presence of a single guide wire and therefore procedure times are reduced. The system is versatile and can be used in other indications. With this technique, two separate balloon catheters are positioned on a single guidewire. The first catheter, with only a distal guidewire lumen, is introduced into the vein and then advanced into the mitral orifice. Subsequently, a rapid exchange balloon catheter running on the same guidewire is inserted and lined up with the first catheter so the two are positioned side by side. Both balloons are then inflated simultaneously ${ }^{[36]}$.

\section{THE INOUE TECHNIQUE OF PMV}

Nowadays, PMV is more frequently performed using the Inoue technique as previously reported $[\text { Figure } 7]^{[4,16,18,22,37]}$. The Inoue balloon is a 12 French shaft, coaxial, double lumen catheter, made of a double layer of rubber tubing with a layer of synthetic micromesh in between. After transseptal catheterization, a stainless-steel guide wire is advanced through the transseptal catheter and placed with its tip coiled into the left atrium and the transseptal catheter removed. Subsequently, a 14 French dilator is advanced over the guide wire and used to dilate the femoral vein and the atrial septum. An Inoue balloon catheter chosen according to the patient's height is advanced over the guide wire into the left atrium. The distal part of the balloon is inflated and advanced into the left ventricle with the help of the spring wire stylet 


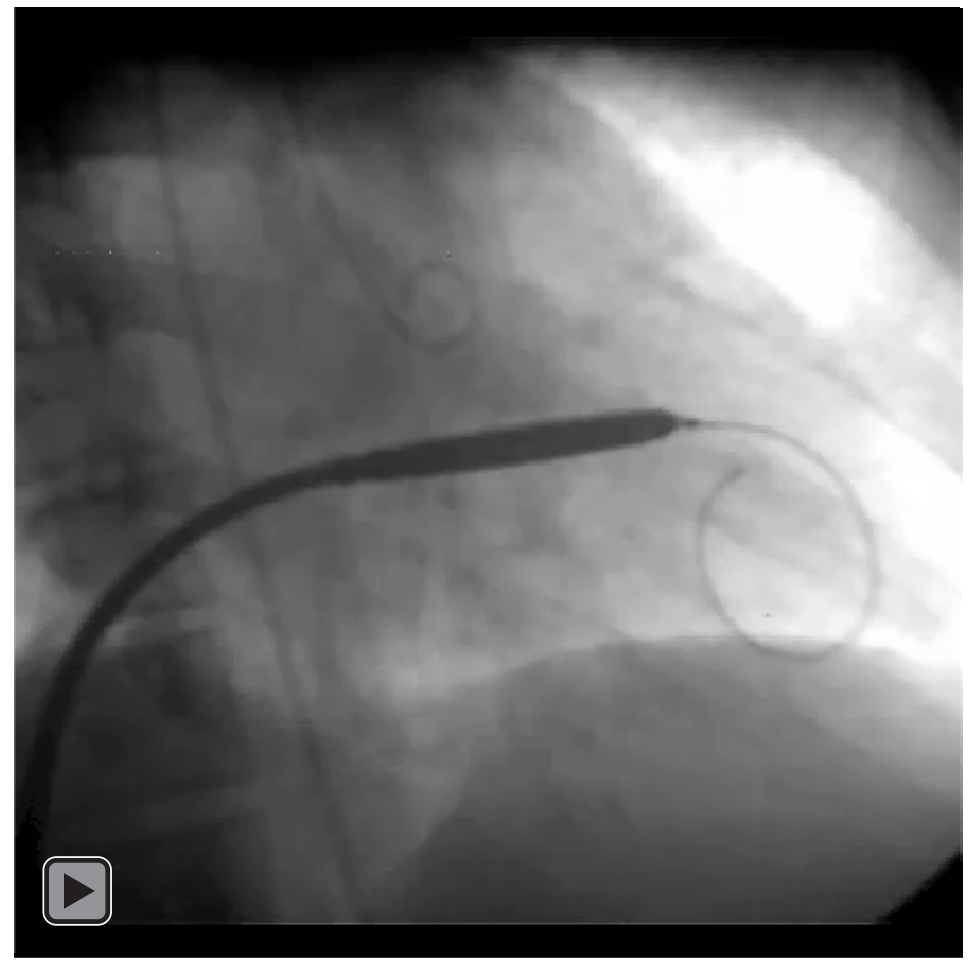

Figure 8. The Cribier metallic dilator technique of percutaneous mitral balloon valvuloplasty

which has been inserted through the inner lumen of the catheter. Once the catheter is in the left ventricle, the partially inflated balloon is moved back and forth inside the left ventricle to assure that is free of the chordae tendineae. The catheter is then gently pulled against the mitral plane until resistance is felt. The balloon is then rapidly inflated to its full capacity and then deflated quickly. During inflation of the balloon an indentation should be seen in its middle portion. The catheter is withdrawn into the left atrium and the mitral gradient and cardiac output are measured. If further dilatations are required, the stylet is introduced again, and the sequence of steps described above are repeated at a larger balloon volume. After each dilatation, its effect should be assessed by pressure measurement, auscultation, and 2D-echocardiography. If mitral regurgitation occurs or worsens, further dilation of the valve should not be performed.

\section{A RETROGRADE TECHNIQUE OF PMV}

In the retrograde technique of PMV described by Babic ${ }^{[33]}$, the balloon dilating catheters are advanced percutaneously through the right and left femoral arteries over guide wires that have been snared from the descending aorta ${ }^{[33]}$. With the Babic technique these guide wires have been advanced transeptally from the right femoral vein into the left atrium, the left ventricle, and then the ascending aorta ${ }^{[33]}$. A transaortic retrograde non-transseptal technique of PMV has been described by Stefanadis ${ }^{[34,35]}$.

\section{A METALLIC VALVULOTOMY CATHETER TECHNIQUE OF PMV}

A technique of PMV using a newly designed metallic valvulotomy catheter was introduced by Cribier et al. ${ }^{[38,39]}$ [Figure 8]. The device consists of a detachable metallic cylinder with 2 articulated bars screwed onto the distal end of a disposable catheter whose proximal end is connected to activating pliers. Squeezing the pliers opens the bars up to a maximum of $40 \mathrm{~mm}$. The results with this device are at least comparable to those of the other balloon techniques of PMV. However, multiple uses after sterilization should markedly decrease procedural costs ${ }^{[3,39]}$. 


\section{Transseptal Left Heart Catheterization}

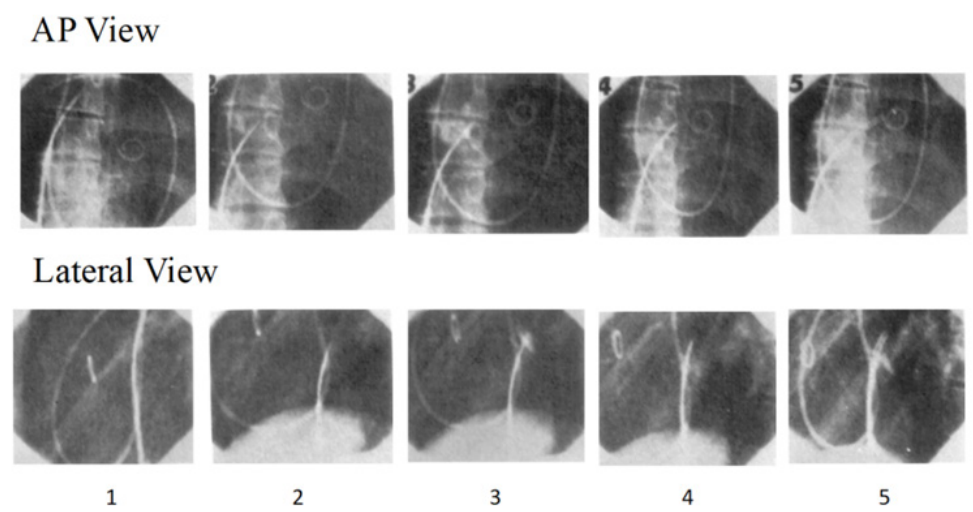

Figure 9. Transseptal left heart catheterization as viewed by anteroposterior (upper) and lateral fluoroscopy (bottom). Modified from Roelke M, Smith AJ, Palacios IF. The technique and safety of transseptal left heart catheterization: the Massachusetts General Hospital experience with 1,279 procedures ${ }^{[51]}$

\section{TRANSSEPTAL LEFT HEART CATHETERIZATION}

Transseptal catheterization is performed using the percutaneous technique from the right femoral vein as previously described ${ }^{[40,41]}$. Biplane fluoroscopy, if available, is the ideal imaging system. However, a single plane "C" arm fluoroscope, which can be rotated from the antero-posterior to lateral position, may also be used [Figure 9]. A pigtail catheter is positioned retrogradely in the right coronary sinus to correctly identify the aorta [Figure 9]. A detailed description of the procedure is well outlined in the article by Roelke et $_{\mathrm{al}}{ }^{[40]}$. The use of transesophageal or intracardiac echocardiography add on the safety and success of the procedure ${ }^{[40,41]}$. When positioned at the target septal spot, the tip of the Brockenbrough needle is advanced into the left atrium under continuous fluoroscopic, echocardiographic and pressure monitoring. Septal penetration is heralded by a change from the right atrial to left atrial pressure measurement and by injecting contrast, which should flow freely into the left atrium. Slight variations in the technique may be required with different interventional procedures [Figure 10]. During double balloon PMV and with the Cribier metallic valvulotomy catheter, a low puncture site in the middle posterior third of the septum provides a straight pathway to the mitral orifice and apex of the left ventricle to facilitate manipulation of guidewires and catheters. A slightly higher puncture is preferred when using a single Inoue balloon to allow the straightest course for the flow directed distal balloon through the mitral valve [Figure 10].

\section{IMMEDIATE RESULTS}

The technique of PMV has now been evaluated in several thousands of patients with different clinical situations. Immediate and long-term results of PMV can be assessed in the catheterization laboratory using hemodynamics or by echocardiography ${ }^{[42,43]}$. The use of echocardiography in the catheterization laboratory during PMV is important because it enables the detection of early complications and provides essential information on the course of the mitral valve opening. The following criteria been proposed for the desired end point of the procedure: post-PMV mitral valve area (MVA) $\geq 1.5 \mathrm{~cm}^{2}$ or $>1.0 \mathrm{~cm}^{2} / \mathrm{m}^{2}$ body surface area or $\geq 50 \%$ increase in post-PMV MVA, complete opening of at least 1 commissure, and appearance or increment of mitral regurgitation $>1+$ in the Sellers 0 to $4+$ classification $^{[39]}$. After the procedure, the most accurate evaluation of valve area is given by echocardiography using planimetry whenever possible; $3 \mathrm{D}$-echocardiography may be helpful to assess the post-dilation results in terms of anatomical effects and changes of residual mitral regurgitation. PMV usually allows for a doubling in valve area, with a final valve 


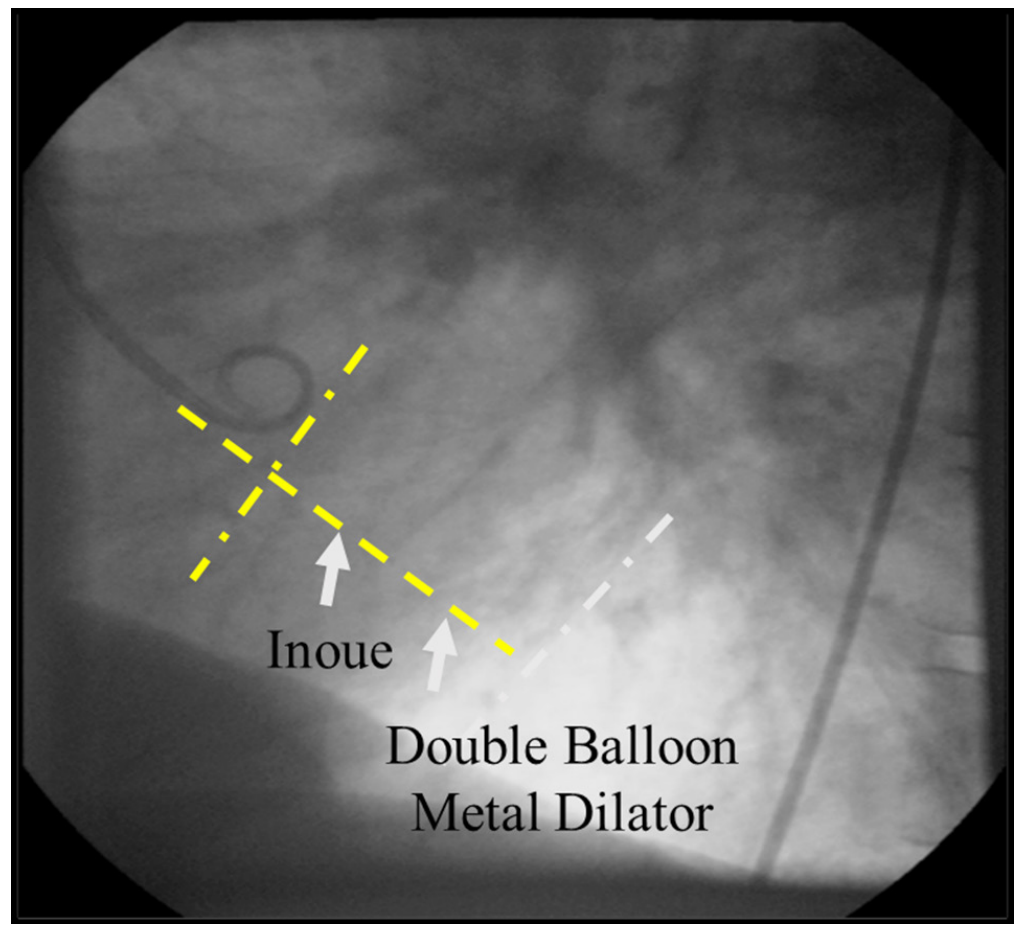

Figure 10. More selective site of transseptal puncture according procedure to be performed after completion of successful transseptal left heart catheterization. Modified from Palacios IF. Percutaneous mitral balloon valvuloplasty for patients with rheumatic mitral stenosis. In: Herrmann $\mathrm{HC}$, editor ${ }^{[1]}$, with permission

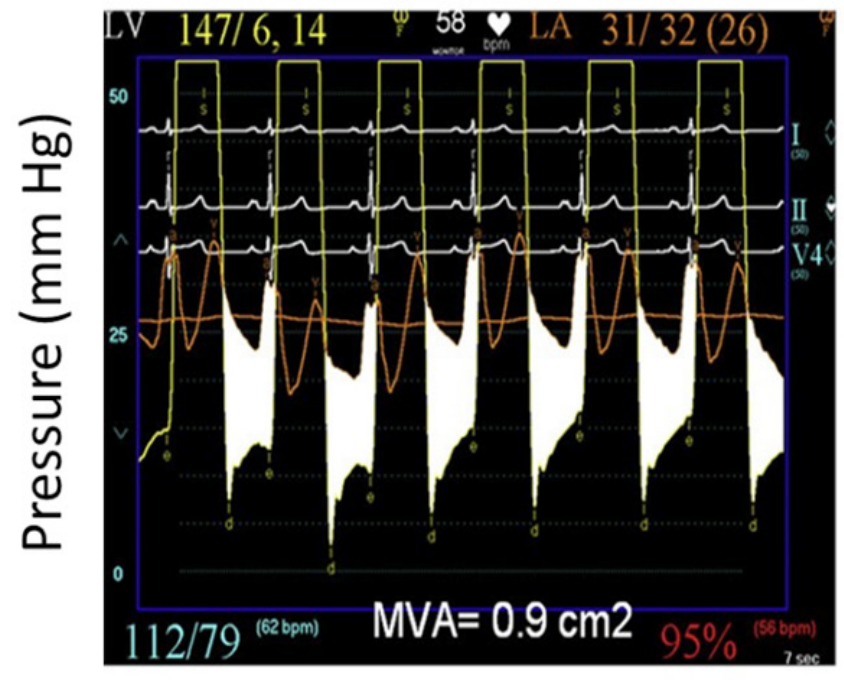

LV/LA Pre-PMV

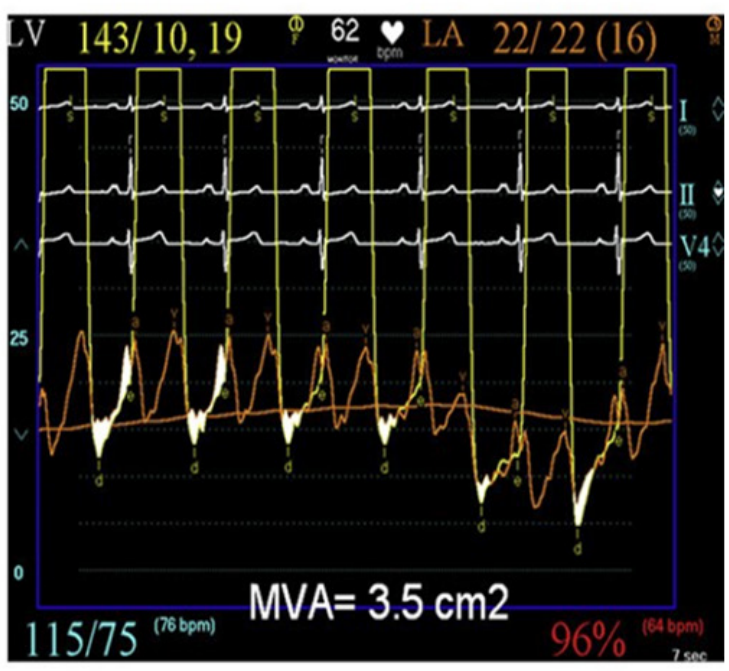

LV/LA Post-PMV

Figure 11. Hemodynamic changes produced by a successful PMV in one patient with severe mitral stenosis. Simultaneous left atrium (LA) and left ventricular (LV) pressures before (left) and after (right) double balloon PMV. The corresponding calculated MVAs are also displayed (From Palacios IF. Percutaneous mitral balloon valvuloplasty for patients with rheumatic mitral stenosis. In: Herrmann HC, editor. Interventional Cardiology: Percutaneous Noncoronary Intervention ${ }^{[1]}$, with permission). PMV: percutaneous mitral balloon valvuloplasty; MVA: mitral valve area

area $>2.0 \mathrm{~cm}^{2}$ on average. The improvement in valve function results in an immediate decrease in left atrial and pulmonary pressures both at rest and during exercise. Figure 11 depicts the pre-PMV and post-PMV hemodynamic of one patient who underwent a successful and optimal PMV using the double-balloon 
technique. PMV resulted in a substantial decrease in trans mitral gradient and an increase in MVA from $0.9 \mathrm{~cm}^{2}$ to $3.5 \mathrm{~cm}^{2}$. Table 2 depicts changes in mitral valve area after PMV from different institutions with large PMV series.

The predictors of the immediate results of PMV are multifactorial. In addition to the morphological factors, preoperative variables (such as age, history of previous surgical commissurotomy, New York Heart Association functional class of heart failure, smaller initial mitral valve area, and presence of tricuspid regurgitation), and procedural factors (such as the non-use of Inoue technique) have been identified as independent predictors of poor immediate results of $\mathrm{PMV}^{[6,10,15,16]}$.

\section{MECHANISM OF PMV}

The mechanism of successful PMV is splitting of the fused commissures toward the mitral annulus, resulting in commissural widening. This mechanism has been demonstrated by pathologic, surgical, and echocardiographic studies ${ }^{[7,12,42,43]}$. In addition, in patients with calcific mitral stenosis, the balloons could increase mitral valve flexibility by the fracture of the calcified deposits in the mitral valve leaflets. Although rare, undesirable complications, such as leaflets tears, left ventricular perforation, tear of the atrial septum, and rupture of chordae, mitral annulus, and papillary muscle, could also occur ${ }^{[44]}$.

\section{RISKS AND COMPLICATIONS}

The failure rates range from $1 \%$ to $15 \%$, and they reflect primarily the learning curve of the operators $^{[8,9,12,16,37]}$. Table 3 depicts rate of complications from PMV from different centers with high volume of PMV. Procedural mortality ranges from $0 \%$ to $3 \%$. The incidence of hemopericardium varies from 0.5 to $12 \%$. Embolism is encountered in $0.5 \%$ to $5 \%$ of cases. Severe mitral regurgitation is the most worrying complication ${ }^{[21,25,26,37]}$. It occurs in $2 \%$ to $10 \%$ of patients and results from non-commissural leaflet tearing, primarily in cases with unfavorable anatomy, and even more so if there is a heterogeneous distribution of the morphological abnormalities ${ }^{[25,26]}$. Surgery is often necessary later and can be conservative in cases with less severe valve deformity. Although urgent surgery is seldom needed for complications $(<1 \%$ in experienced centers), it may be required for massive hemopericardium or, less frequently, for severe mitral regurgitation, leading to hemodynamic collapse or refractory pulmonary edema. Immediately after PMV, color Doppler echo shows small interatrial shunts in most patients. PMV is associated with a $15 \%$ incidence of left-to-right shunt immediately after the procedure. The pulmonary-to-systemic flow ratio is < 1.5:1 in the majority of the patients. The incidence of left-to-right shunt through the atrial communication is greater in patients with echocardiographic scores $>8^{[45]}$. Casale et al ${ }^{[45]}$ reported the results of post-PMV left to right shunting in 150 patients who underwent PMV at the Massachusetts General Hospital. A left to right shunt through the created atrial communication was present in 28 patients (19\%) after $\mathrm{PMV}^{[46]}$. The pulmonary to systemic flow ratio was $>2: 1$ in 4 patients and $<2: 1$ in 24 . Univariate predictors of left to right shunting after valvuloplasty included older age $(P<0.01)$, lower cardiac output before mitral valvuloplasty $(P<0.01)$, higher New York Heart Association functional class before PMV $(P<0.05)$, presence of mitral valve calcification under fluoroscopy $(P<0.01)$ and higher Echo-Score $(P<0.05)$. Multiple stepwise logistic regression analysis identified the presence of mitral valve calcification $(P<0.02)$ and lower cardiac output $(P<0.02)$ as independent predictors of a left to right shunt through the atrial communication after PMV. A persistent atrial septal defect was demonstrated by oximetry in only 5 of 13 patients who underwent elective right heart catheterization at $11 \pm 1$ months after mitral valvuloplasty. Doppler color flow echo cardiography demonstrated a left to right shunt in only one of the remaining three patients who did not undergo catheterization. Thus, 13 (59\%) of 22 patients who had a left to right shunt after PMV were demonstrated to have no evidence of residual left to right shunt through the created atrial communication at $10 \pm 1$-month follow-up study ${ }^{[45]}$. 
Table 4. Clinical long-term follow-up after PMV

\begin{tabular}{|c|c|c|c|c|c|}
\hline Author & \# Patients & Age & Follow up (years) & Survival & Event-free \\
\hline Palacios et al. ${ }^{[10]}$ & 879 & 55 & 12 & $87 \%$ & $53 \%$ \\
\hline Lung et al. ${ }^{[22]}$ & 1,024 & 49 & 10 & $85 \%$ & $56 \%$ \\
\hline Hernandez et al. ${ }^{[17]}$ & 561 & 53 & 7 & $95 \%$ & $69 \%$ \\
\hline Orrange et $a{ }^{[64]}$ & 132 & 44 & 7 & $83 \%$ & $65 \%$ \\
\hline Reyes et al. ${ }^{[65]}$ & 30 & 29 & 7 & $100 \%$ & $90 \%$ \\
\hline Stefanadis et al. ${ }^{[35]}$ & 441 & 44 & 9 & $98 \%$ & $75 \%$ \\
\hline
\end{tabular}

Modified from Palacios IF. Percutaneous mitral balloon valvuloplasty for patients with rheumatic mitral stenosis ${ }^{[1]}$. PMV: percutaneous mitral balloon valvuloplasty

\section{LONG-TERM RESULTS}

We are now able to analyze follow-up data up to 15 years $^{[9,12-14,16]}$. Several large single-center series confirm the late efficacy of PMV in a large population comprising a variety of patient subsets [Table 4]. Late outcome after PMV differs according to the quality of the immediate results. In a series of 879 patients undergoing PMV at the Massachusetts General Hospital, we reported a completed follow-up in 575 (96\%) of patients with Echo-Sc $\leq 8$ and in 269 (97\%) of patients with Echo-Sc $>8^{[9]}$. For the entire population, there were $110(12.5 \%)$ deaths (25 of which were non-cardiac), $234(26.6 \%)$ mitral valve replacements (MVRs), and $54(6.14 \%)$ redo PMVs, accounting for a total of 398 (45.3\%) patients with combined events (death, MVR, or redo PMV). Of the remaining 446 patients that were free of combined events, 418 (94\%) were in New York Heart Association (NYHA) class I or II. Follow-up events occurred less frequently in patients with Echo-Sc $\leq 8$ and included 51 (8.4\%) deaths, 155 (25.8\%) MVRs, and 39 (6.49\%) redo PMVs, accounting for a total of $245(40.7 \%)$ patients with combined events at follow-up. Of the remaining 330 patients who were free of combined events, 312 (95\%) were in NYHA class I or II. Follow-up events in patients with Echo-Sc > 8 included 59 (21.2\%) deaths, 79 (28.4\%) MVRs, and 15 (5.4\%) redo PMVs, accounting for a total of $153(55.03 \%)$ patients with combined events at follow-up. Of the remaining 116 patients who were free of any event, 105 (91\%) were in NYHA class I or $\mathrm{II}^{[9]}$. Figures 12, 13, and 14 show the Kaplan-Meier survival and event free survival estimates for all patients, subdivided by patients with Echo-Sc $\leq 8$ and $>8$ and patients with Echo-Sc $\geq 12$ [Figure 14].

Although adverse events (death, mitral valve surgery, and redo PMV) were low within the first 5 years of follow-up, a progressive number of events occurred beyond this period. Nevertheless, survival ( $82 \% v s$. $57 \%)$ and event-free survival $(57.4 \%$ vs. $43.1 \%)$ at 12 -year follow-up was greater in patients with Echo-Sc $\leq 8$ compared to patients with Echo-Sc $>8(P<0.0001)$. Cox regression analysis identified post-PMV mitral regurgitation $\geq$ grade $3+$, Echo-Sc $>8$, older age, prior surgical commissurotomy, NYHA functional class IV, pre-PMV mitral regurgitation $\geq 2+$, and higher post-PMV pulmonary artery pressure as independent predictors of combined events at long-term follow-up ${ }^{[9]}$.

\section{PMV VS. SURGICAL COMMISSUROTOMY}

Several studies have compared the immediate and early follow-up results of PMV vs. open or closed surgical commissurotomy. These initial trials results of PMV vs. surgical commissurotomy are encouraging and favor PMV for the treatment of patients with rheumatic mitral stenosis with suitable mitral valve morphology ${ }^{[10,21-23,47]}$. Thus, it seems reasonable to recommend PMV for patients with Echo-Sc $\leq 8$, especially if they have other favorable characteristics (age $<45$ years, $\leq 2+\mathrm{MR}$, and no previous mitral surgery). The question remains as to which procedure, MVR or PMV, is more suitable for patients with Echo-Sc $>$ 8. A successful PMV result is obtained in $56.4 \%$ of these patients, and only $43.1 \%$ of them were free of combined events at the 12-year follow-up. Because a good immediate outcome was achieved in $61 \%$ of patients with Echo-Sc between 9 and 11 and 39\% were free of combined events at 5- year follow-up [Figure 13], PMV might be considered the first choice in these patients if they are free of other risk variables. 


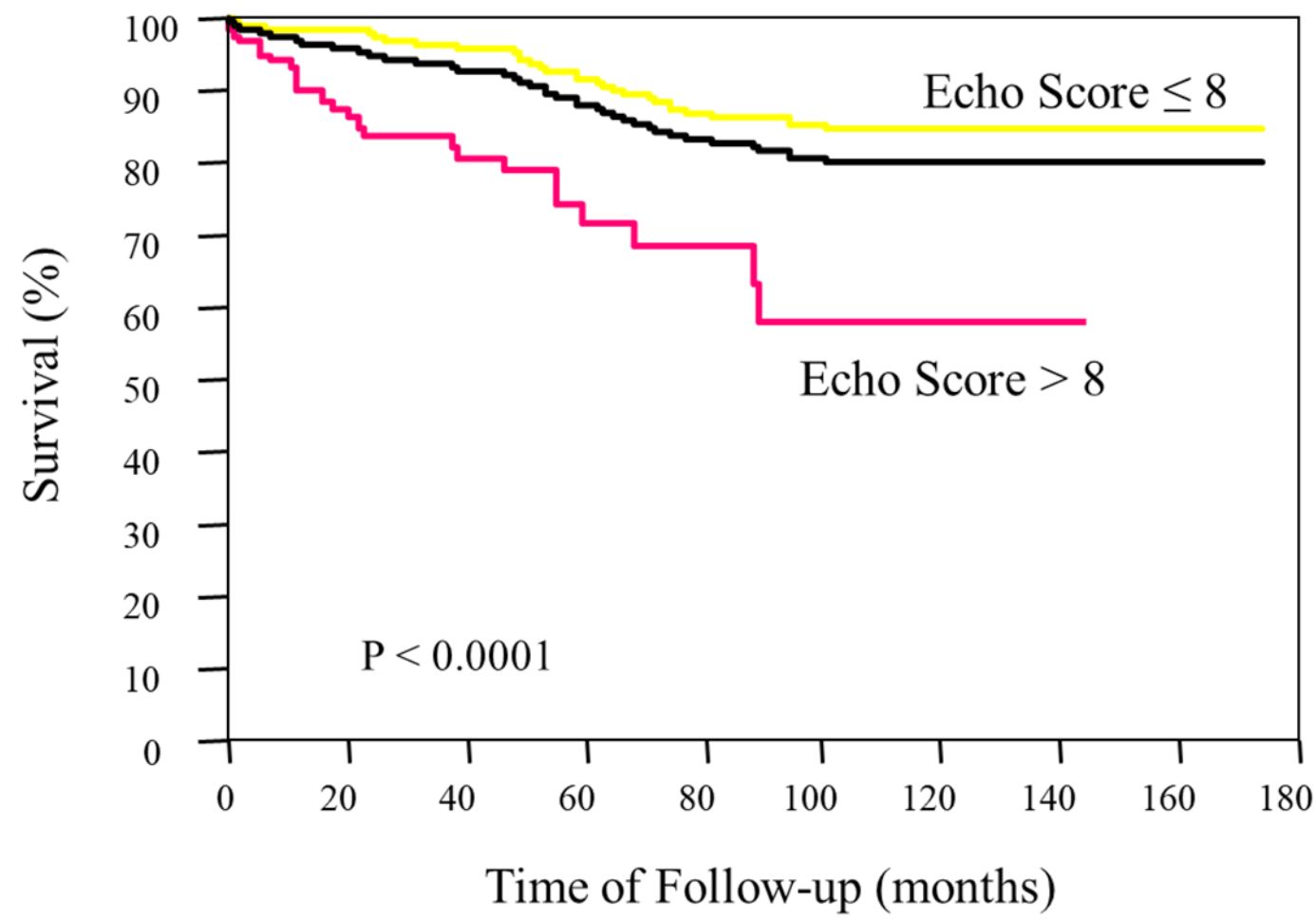

Figure 12. Kaplan-Meier survival estimates for all patients and for patients with Echo-Sc $\leq 8$ and $>8$. Modified from Palacios IF, Sanchez PL, Harrell LC, Weyman AE, Block PC. Which patients benefit from percutaneous mitral balloon valvuloplasty? Pre and post-valvuloplasty variables that predict 15 -year outcome ${ }^{[13]}$

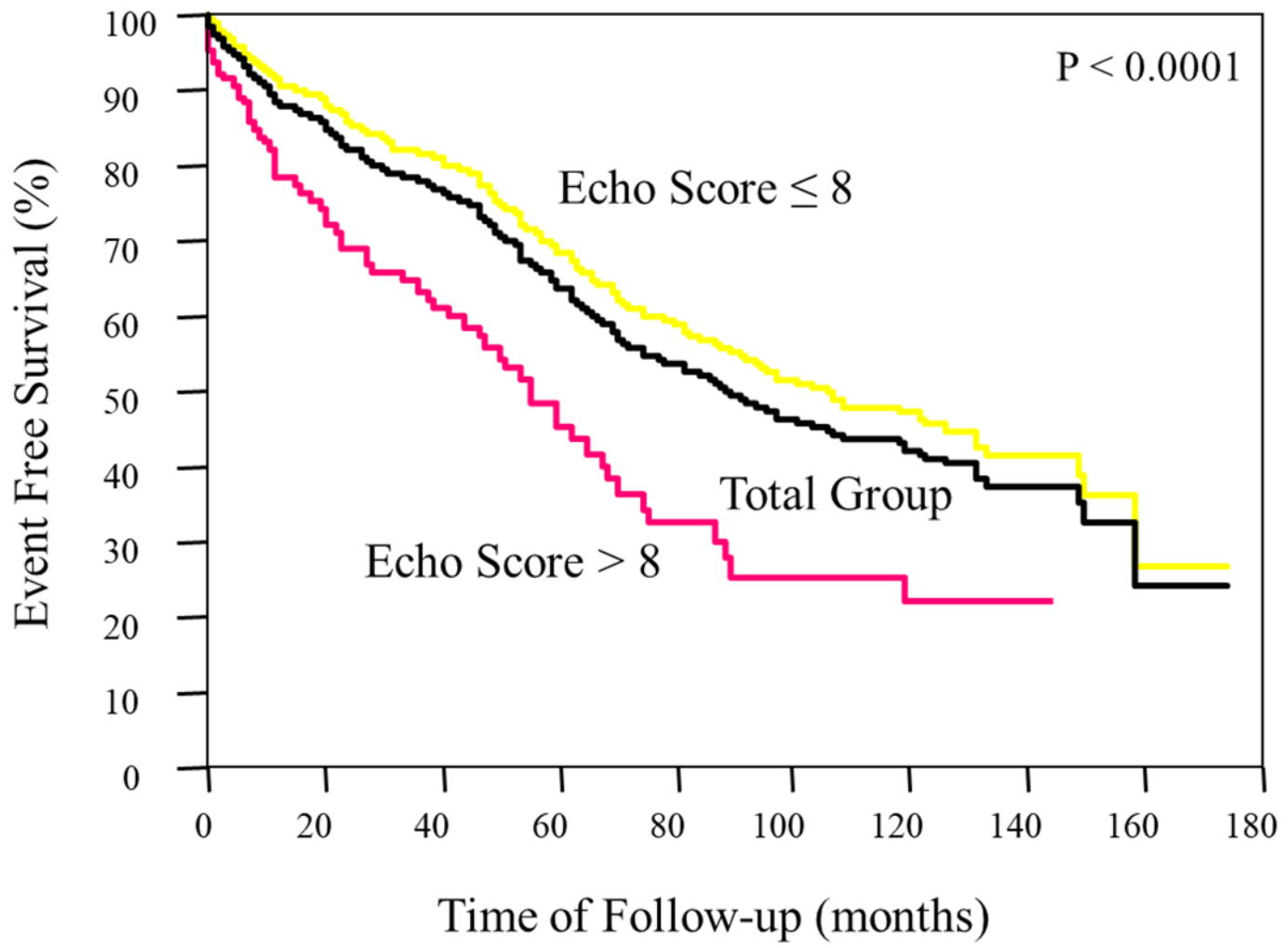

Figure 13. Kaplan-Meier event-free survival estimates (alive and free of MVR or redo PMV) for all patients and for patients with Echo Sc $\leq 8$ and $>8$. Modified from Palacios IF, Sanchez PL, Harrell LC, Weyman AE, Block PC. Which patients benefit from percutaneous mitral balloon valvuloplasty? Pre and post -valvuloplasty variables that predict 15-year outcome ${ }^{[13]}$. PMV: percutaneous mitral balloon valvuloplasty; MVR: mitral valve replacement 


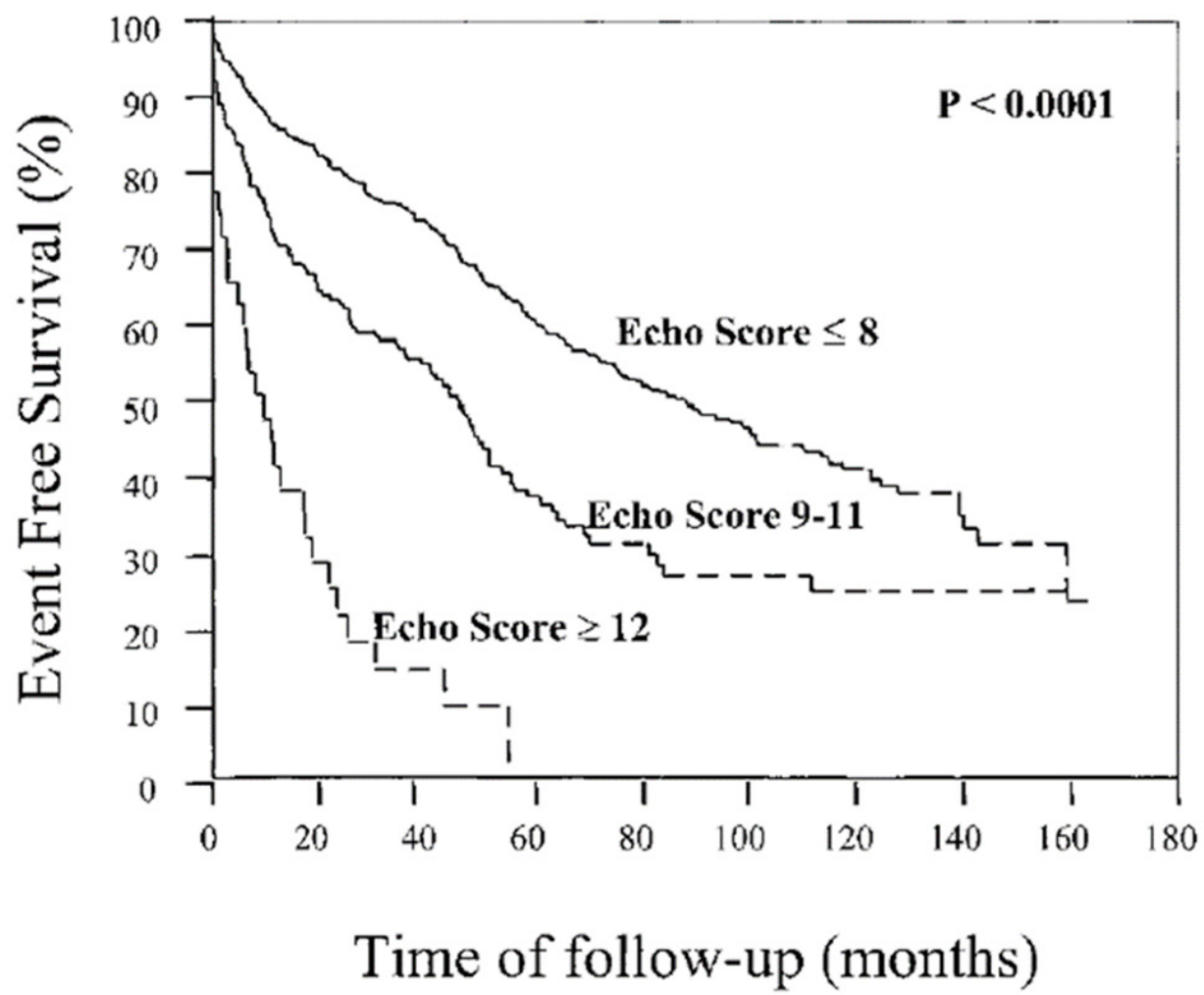

Figure 14. Kaplan-Meier event-free survival estimates (alive and free of MVR or redo PMV) for patients with Echo-Sc $\leq 8$, Echo-Sc 9 to 11 , and Echo-Sc $\geq 12$. Modified from Palacios IF, Sanchez PL, Harrell LC, Weyman AE, Block PC. Which patients benefit from percutaneous mitral balloon valvuloplasty? Pre and post-valvuloplasty variables that predict $15-y e a r$ outcome ${ }^{[13]}$. PMV: percutaneous mitral balloon valvuloplasty; MVR: mitral valve replacement

Conversely, patients with Echo-Sc $\geq 12$ should be referred for MVR, because only $36 \%$ had successful PMV and only $10 \%$ were free of events at 4 years post-PMV [Figure 14]. Nevertheless, PMV could be considered as a palliative procedure if the patients are non or very high surgical candidates.

\section{PMV IN PATIENTS WITH PREVIOUS SURGICAL COMMISSUROTOMY}

Although the increase in MVA with PMV is inversely related to the presence of previous surgical mitral commissurotomy, PMV can produce a good outcome in this group of patients. The post-PMV mean MVA in 154 patients with previous surgical commissurotomy was $1.8 \pm 0.7 \mathrm{~cm}^{2}$ compared with an MVA of $1.9 \pm 0.6 \mathrm{~cm}^{2}$ in patients without previous surgical commissurotomy $\left.P<0.05\right)$. In this group of patients, an echocardiographic score $\leq 8$ was an important predictor of a successful hemodynamic immediate outcome $^{[48]}$. This application for PMV assumes that the mechanism of restenosis after surgical mitral commissurotomy is due to commissural fusion as determined by echocardiography.

\section{REDO PMV IN PATIENTS WITH POST-PMV MITRAL RESTENOSIS}

PMV for mitral restenosis is feasible, safe, and achieves immediate and long-term outcome comparable to initial $\mathrm{PMV}^{[49]}$. We reported the immediate outcome and long-term clinical follow-up results of 36 patients (mean age $58 \pm 13$ years, 75\% women) with symptomatic mitral restenosis after prior PMV, who were treated with a repeat PMV at $34.6 \pm 28$ months after the initial $\mathrm{PMV}^{[49]}$. The mean follow-up period was 30 \pm 33 months with a maximal follow-up of 10 years. An immediate procedural success was obtained in $75 \%$ patients. The overall survival rate was $74 \%, 72 \%$, and $71 \%$ at one, two, and three years, respectively. The event-free survival rate was $61 \%, 54 \%$ and $47 \%$ at one, two, and three years, respectively. In the presence 
of comorbid diseases (cardiac and noncardiac), the two-year event-free survival was reduced to $29 \%$ as compared with $86 \%$ in patients without comorbid diseases. Cox regression analysis identified Echo-Score $(P$ $=0.03)$, post-PMV mitral valve area $(P=0.003)$, post-PMV mitral regurgitation grade $(P=0.02)$ and postPMV pulmonary artery pressure $(P=0.0001)$ as independent predictors of event-free survival after repeat PMV. We concluded that repeat PMV for post-PMV mitral restenosis results in good immediate and longterm outcome, particularly in patients with restenosis due to commissure fusion, low echocardiographic scores, and absence of comorbid diseases. Although the results are less favorable in patients with suboptimal characteristics, repeat PMV has a palliative role if the patients are not or very high surgical candidates $^{[49]}$.

\section{PMV AND AGE}

Sanchez et al. ${ }^{[24]}$ reported the impact of age in the immediate and long-term outcome of PMV. For purpose of analysis, these patients were divided into four age groups: group 1 ( $\leq 35$ years), group 2 (36-55 years), group 3 (56-75 years), and group 4 (> 75 years). The incidence of atrial fibrillation, calcified valves under fluoroscopy, higher echocardiographic score, NYHA class IV, and pre-PMV MR increased with patient's age. As patients became older, a lower post-PMV mitral valve area $\left(2.1 \pm 0.7 \mathrm{~cm}^{2}, 2.0 \pm 0.6 \mathrm{~cm}^{2}, 1.8 \pm 0.6 \mathrm{~cm}^{2}\right.$, and $\left.1.6 \pm 0.6 \mathrm{~cm}^{2} ; P<0.0001\right)$ and progressive decrease in procedural success $(81.4 \%, 80.5 \%, 65.3 \%$, and 53\%; $P<0.0001)$ were observed. Younger age was identified as an independent predictor of PMV success by multiple stepwise logistic regression [odds ratio: 3.33; confidence interval (CI): 1.41-7.69, $P=0.006$ ]. Furthermore, age was identified as an independent predictor of long-term events by Cox regression analysis [risk ratio: 1.02; CI: 1.01-1.03, $P<0.00001$ ]. However, the effect of age seemed to be blunted by the morphology of the valve at follow-up, as patients with Echo-Sc greater than 8 in groups 2, 3, and 4 presented similar combined event-free survival (death, mitral valve replacement, or redo PMV). They concluded that age is an important predictor of immediate and long-term outcomes after PMV, particularly in patients with optimal mitral valve morphology ${ }^{[20,24,50]}$.

\section{PMV AND PREGNANCY}

Surgical mitral commissurotomy has been performed in pregnant women with severe mitral stenosis. Because the risk of anesthesia and surgery for the mother and the fetus are increased, this operation is reserved for those patients with incapacitating symptoms refractory to medical therapy ${ }^{[51]}$. Under these conditions, PMV can be performed safely after the twentieth week of pregnancy with minimal radiation to the fetus ${ }^{[51,52]}$. Because of the definite risk in women with severe mitral stenosis of developing symptoms during pregnancy, PMV should be considered when a patient is considering becoming pregnant and has evidence of severe mitral stenosis. Esteves et al. ${ }^{[52]}$ reported that PMV can be performed during pregnancy without significant maternal risk or fetal morbidity or mortality. They report the results of 71 consecutive pregnant women with severe rheumatic mitral stenosis and severe congestive heart failure (New York Heart Association class III and IV) referred for PMV. All patients underwent clinical and obstetric evaluations, electrocardiography, and 2-dimensional and Doppler echocardiography. PMV was successful in all patients, resulting in a significant increase in mitral valve area from $0.9 \pm 0.2 \mathrm{~cm}^{2}$ to $2.0 \pm 0.3 \mathrm{~cm}^{2}(P<0.001)$. At the end of pregnancy, $98 \%$ of the patients were in New York Heart Association functional class I or II. At a mean follow-up of $44 \pm 31$ months, the total event-free survival rate was $54 \%$. The mean gestational age at delivery time was $38 \pm 1$ weeks. Preterm deliveries occurred in 9 patients (13\%), including 2 twin pregnancies. The remaining 66 of 75 newborns (88\%) had normal weight (mean $2.8 \pm 0.6 \mathrm{~kg}$ ) at delivery. At long-term follow-up of $44 \pm 31$ months after birth, the 66 children exhibited normal growth and development and did not show any clinical abnormalities. They concluded that during pregnancy PMV is safe and effective, has a low morbidity and mortality rate for the mother and the fetus, and has favorable long-term results in pregnant women with rheumatic mitral stenosis in New York Heart Association functional class III or IV ${ }^{[51,52]}$. 

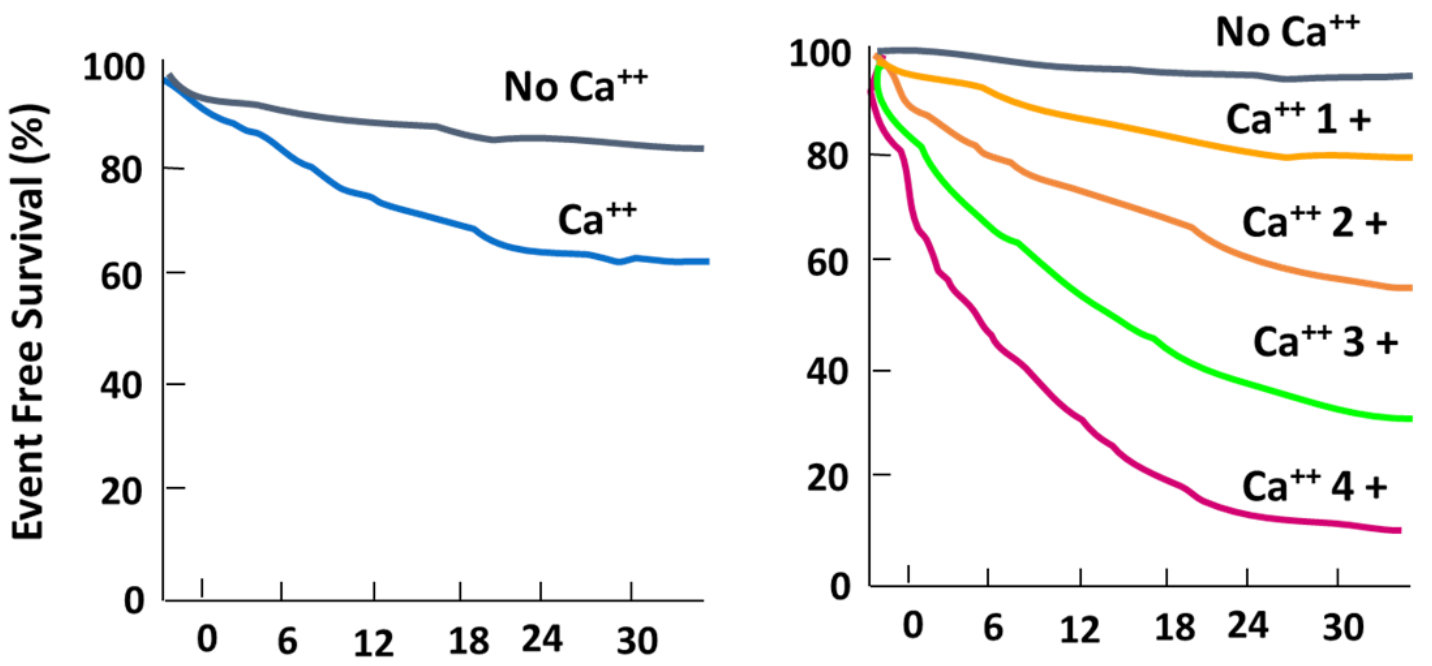

\section{Time of follow-up (months)}

Figure 15. Estimated survival rate at 2 years after percutaneous mitral balloon valvuloplasty, stratified by severity of calcification. Ca 0 to Ca 4+. Modified from Tuzcu EM, Block PC, Griffin B, Dinsmore R, Newell JB, Palacios IF. Percutaneous mitral balloon valvotomy in patients with calcific mitral stenosis: immediate and long-term outcome ${ }^{[53]}$

\section{FOLLOW-UP OF PATIENTS WITH CALCIFIED MITRAL VALVES}

The presence of fluoroscopically visible calcification on the mitral valve influences the success of PMV. Tuzcu et al. ${ }^{[53]}$ reported that patients with heavily $(\geq 3+)$ calcified valves under fluoroscopy have a poorer immediate outcome as reflected in a smaller post-PMV MVA and greater post-PMV mitral valve gradient. Immediate outcome is progressively worse as the calcification becomes more severe. As shown in Figure 15, the long-term results of PMV are significantly different in calcified and uncalcified groups and in subgroups of the calcified group ${ }^{[53,54]}$. The estimated 2 -year survival is significantly lower for patients with calcified mitral valves than for those with uncalcified valves ( $80 \% v$ s. $99 \%)$. The survival curve becomes worse as the severity of valvular calcification becomes more severe. Freedom from mitral valve replacement at 2 years was significantly lower for patients with calcified valves than for those with uncalcified valves ( $67 \%$ vs. 93\%). Similarly, the estimated event-free survival at 2 years in the calcified group became significantly poorer as the severity of calcification increased. The estimated event-free survival at 2 years was significantly lower for the calcified than for the uncalcified group (63\%vs. 88\%). The actuarial survival curves with freedom from combined events at 2 years in the calcified group became significantly poorer as the severity of calcification increased. These findings are in agreement with several follow-up studies of surgical commissurotomy, which demonstrate that patients with calcified mitral valves had a poorer survival compared with those with uncalcified valves ${ }^{[53,55]}$.

\section{FOLLOW-UP OF PATIENTS WITH ATRIAL FIBRILLATION}

Leon et al.$^{[54]}$ reported that the presence of atrial fibrillation is associated with inferior immediate and longterm outcome after PMV as reflected in a smaller post-PMV MVA and a lower event-free survival (freedom from death, redo-PMV, and mitral valve surgery) at a median follow-up time of 61 months (32\% vs. $61 \% ; P$ $<0.0001)$. Analysis of pre-procedural and procedural characteristics revealed that this association is most likely explained by the presence of multiple factors in the atrial fibrillation group that adversely affect the immediate and long-term outcome of PMV. Patients in atrial fibrillation are older and presented more frequently with NYHA class IV, Echo-Sc greater than 8, calcified valves under fluoroscopy, and a history of previous surgical commissurotomy. In the group of patients in atrial fibrillation, the authors identified severe post-PMV MR $(>31)(P<0.0001)$, echocardiographic score greater than $8(P=0.004)$, and pre- 
PMV NYHA class IV $(P=0.046)$ as independent predictors of combined events at follow-up. The presence of atrial fibrillation per se should not be the only determinant in the decision process regarding treatment options in patients with rheumatic mitral stenosis. The presence of an Echo-Sc less than or equal to 8 primarily identifies a subgroup of patients in atrial fibrillation in whom percutaneous balloon valvotomy is likely to be successful and provide good long-term results. Therefore, in this group of atrial fibrillation patients, PMV should be the procedure of choice for the treatment of rheumatic mitral stenosis ${ }^{[54]}$.

\section{PMV IN PATIENTS WITH AORTIC REGURGITATION}

Sanchez-Ledesma et al. ${ }^{[56]}$ examine the effect of concomitant aortic regurgitation (AR) on PMV procedural success, short-term, and long-term clinical outcome in 676 procedures performed. Of which, 361 (53.4\%) had no AR, 287 (42.5\%) mild AR, and 28 (4.1\%) moderate AR. There were no differences between groups in the pre-procedure characteristics, procedural success, or in the incidence of in-hospital adverse events. At a median follow-up of 4.11 years, there was no difference in the overall survival rate $(P=0.22)$, MVR rate $(P=0.69)$, or redo PMV incidence $(P=0.33)$. The rate of AVR was higher in the moderate AR group (0.9\% vs. $1.9 \%$ vs. $13 \%, P=0.003)$. Mean time to AVR was 4.5 years and did not differ significantly between patients with no AR, mild AR, or moderate AR $(2.9 \pm 2.1$ vs. $5.7 \pm v s .4 .1 \pm 2.5$ years, $P=0.46)$. They concluded that concomitant AR at the time of PMV does not influence procedural success and is not associated with inferior outcome. A minority of patients with MS and moderate AR who undergo PMV will require subsequent AVR on long-term follow-up. Thus, patients with rheumatic MS and mild to moderate $\mathrm{AR}$ remain good candidates for $\mathrm{PMV}^{[56]}$.

\section{THE DOUBLE-BALLOON VS. THE INOUE TECHNIQUES OF PMV}

Today the Inoue approach of PMV is the technique more widely used. There was controversy as to whether the double-balloon or the Inoue technique provided superior immediate and long-term results. We compared the immediate procedural and the long-term clinical outcomes after PMV using the double-balloon technique $(n=659)$ and Inoue technique $(n=233)$. There were no statistically significant differences in baseline clinical and morphologic characteristics between the double-balloon technique and Inoue technique patients. Although the post-PMV MVA was larger with the double-balloon technique (1.94 \pm 0.72 vs. $1.81 \pm 0.58 ; P<0.01)$, success rate $(71.3 \%$ vs. $69.1 \%$; $P=$ not significant), incidence of greater than grade $3+\operatorname{MR}(9 \% v s .9 \%)$, and in-hospital complications were similar. Furthermore, as shown in Figure 16 long-term and event-free survival were similar with both techniques ${ }^{[57,58]}$. In conclusion, both the Inoue and the double-balloon techniques are equally effective techniques of PMV. The procedure of choice should be performed based on the interventionist experience with the technique ${ }^{[57,58]}$.

\section{FOLLOW-UP OF THE BEST PATIENTS}

In patients identified as optimal candidates for PMV, this technique results in excellent immediate and long-term outcome. Optimal candidates for PMV are those patients meeting the following characteristics: (1) age 45 years old or younger; (2) normal sinus rhythm; (3) Echo-Sc $\leq 8$; (4) no history of previous surgical commissurotomy; and (5) pre- PMV MR $\leq 1+$ Sellers grade ${ }^{[10,50]}$. From 879 consecutive patients undergoing PMV at the Massachusetts General Hospital, the authors identified 136 patients with optimal pre-procedure characteristics ${ }^{[10]}$. In these patients, PMV results in an $81 \%$ success rate and a $3.4 \%$ incidence of major in-hospital combined events (death and/or MVR). In these patients, PMV results in a $95 \%$ survival and $61 \%$ event-free survival at the 12 -year follow-up ${ }^{[10,29,55]}$.

\section{PMV IN PATIENTS WITH PULMONARY ARTERY HYPERTENSION}

Patients with mitral stenosis with severe pulmonary hypertension constitute a high-risk subset for surgical commissurotomy or valve replacement. The degree of pulmonary artery hypertension before PMV is inversely related to the immediate and long-term outcome of $\mathrm{PMV}^{[59]}$. Chen and colleagues divided 564 

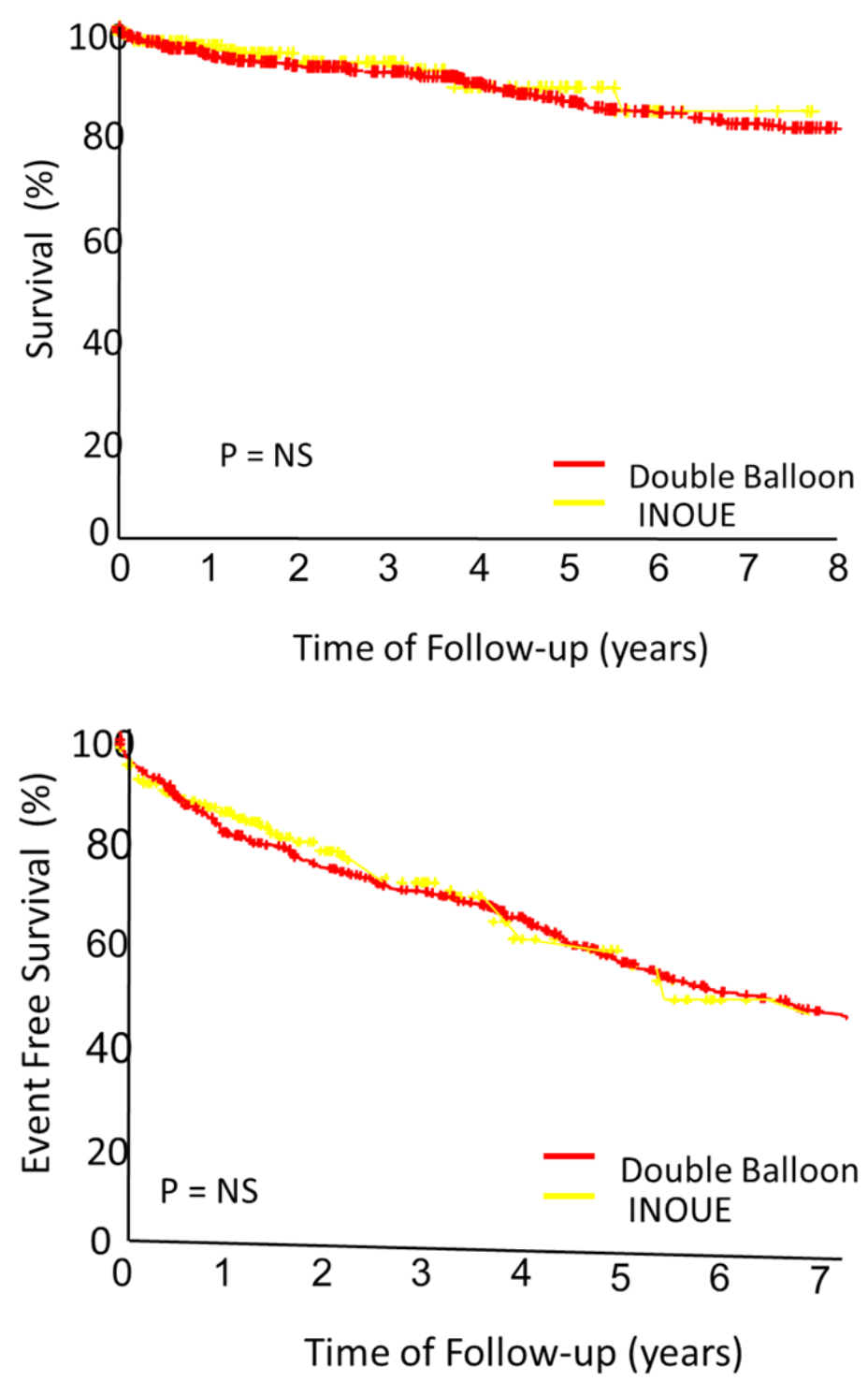

Figure 16. Comparison between the two PMV techniques (Double balloon vs. Inoue balloon) on survival (upper panel) and event-free survival (inferior panel) at long-term follow-up. Modified from Leon MN, Harrell LC, Simosa HF, Mahdi NA, Pathan A, Lopez-Cuellar J, Palacios IF. Comparison of immediate and long-term results of mitral balloon valvotomy with the double balloon vs. Inoue techniques ${ }^{[60]}$. PMV: percutaneous mitral balloon valvuloplasty

patients undergoing PMV at Massachusetts General Hospital into 3 groups on the basis of the pulmonary vascular resistance (PVR) obtained at cardiac catheterization immediately before PMV: group I with less than or equal to 250 dynes $\mathrm{s.cm}{ }^{-5}$ (normal/mildly elevated resistance) comprised 332 patients (59\%), group II with a PVR between 251 and 400250 dynes s.cm $\mathrm{cm}^{-5}$ (moderately elevated resistance) comprised 110 patients (19.5\%), and group III with a PVR greater than or equal to 400 dynes ${\mathrm{s} . \mathrm{cm}^{-5}}^{-5}$ comprised 122 patients (21.5\%). Patients in groups I and II were younger and had less severe heart failure symptoms measured by NYHA class and a lower incidence of Echo-Sc less than 8, atrial fibrillation, and calcium noted on fluoroscopy than patients in group III. Before and after PMV, patients with higher PVR had a smaller MVA, lower cardiac output, and higher mean pulmonary artery pressure. For groups I, II, and III patients, the immediate success rates for PMV were $68 \%, 56 \%$, and $45 \%$, respectively. Therefore, patients in the group with severely elevated pulmonary artery resistance before the procedure had lower immediate success rates of PMV. At long-term follow-up, patients with severely elevated pulmonary vascular resistance had a significant 
lower survival and event-free survival (survival with freedom from mitral valve surgery or NYHA class III or IV heart failure). Furthermore, Cruz-Gonzalez et al. ${ }^{[59]}$ examined the effect of elevated PVR on PMV procedural success, short- and long-term clinical outcomes (i.e., mortality, mitral valve surgery, and redo PMV) in 926 consecutive patients undergoing PMV at the Massachusetts General Hospital. Of the 926 patients, 263 (28.4\%) had PVR $\geq 4$ Woods units (WU) and 663 (71.6\%) had PVR $<4$ WU. Patients with PVR $\geq 4$ WU were older and more symptomatic and had worse valve morphology for PMV. The patients with PVR $\geq 4 \mathrm{WU}$ also had lower PMV procedural success than those with PVR $<4$ WU $(78.2 \%$ vs. 85.6\%, $P=0.006$ ). However, after multivariate adjustment, PVR was no longer an independent predictor of PMV success nor an independent predictor of the combined end point at a median follow-up of 3.2 years. They concluded that elevated PVR at PMV is not an independent predictor of procedural success or long-term outcomes. Therefore, appropriately selected patients with rheumatic mitral stenosis might benefit from $\mathrm{PMV}$, even in the presence of elevated pre-procedural $\mathrm{PVR}^{[59]}$.

\section{TRANSCATHETER MVR, A FUTURISTIC PROMISING APPROACH}

Mitral annulus calcification (MAC) is another disease that could result in severe mitral stenosis or mixed mitral valve disease. Patients with MAC are frequently an elderly high-risk population with multiple comorbidities and a high risk of cardiovascular death and all-cause mortality. The risk of surgical MVR in patients with severe MAC is high. Transcatheter MVR (TMVR) has recently emerged as an exciting new frontier in the field of cardiac structural interventions. Results of the earlier experience with TMVR are encouraging but remain at an early stage ${ }^{[6,61]}$.

\section{PMV IN PATIENTS WITH STENOSED MITRAL BIOPROSTHESIS}

Transcatheter mitral valve-in-valve implantation for dysfunctional biological mitral prosthesis can be performed with minimal operative morbidity and mortality and favorable midterm clinical and hemodynamic outcomes. Nowadays, transcatheter valve in valve has a class IIa indication for bioprosthetic mitral valve degeneration in high-risk to prohibited surgical risk patients according to AHA/ACC 2017 guidelines. However, due to anatomic limitations, not all patients qualify for this procedure and PMV is still an option with symptomatic and hemodynamic benefit. There have been limited reports of successful procedures of balloon valvuloplasty for bioprosthetic mitral valve stenosis. However, there is a need for prospective studies to assess the efficacy and durability of this procedure ${ }^{[62,63]}$.

\section{CONCLUSION}

PMV should be the procedure of choice for the treatment of patients with rheumatic mitral stenosis who are, from clinical and morphologic points of view, optimal candidates for PMV. Patients with Echo-Sc $\leq 8$ have the best results, particularly if they are young, are in normal sinus rhythm, have no pulmonary hypertension, and have no evidence of calcification of the mitral valve under fluoroscopy. The immediate and long-term results of PMV in this group of patients are similar to those reported after surgical mitral commissurotomy. Patients with Echo-Sc $>8$ have only a 50\% chance to obtain a successful hemodynamic result with PMV, and long-term follow-up results are worse than those from patients with Echo-Sc $\leq 8$. In patients with Echo-Sc $\geq 12$, it is unlikely that PMV could produce good immediate or long-term results. They preferably should undergo open heart surgery. PMV could be performed in these patients if they are non- or high-risk surgical candidates. Finally, much remains to be done in refining indications for patients with few or no symptoms and those with unfavorable anatomy. The question remains as to which procedure, MVR or PMV, is more suitable for patients with Echo-Sc $>8$ but $\leq 12$ (the so called the gray zone). Analysis of the individual component of the Echo-Sc could be helpful in decide to proceed with PMV over surgery. Severity of leaflet thickening and degree of sub valvular disease would favor MVR, while mobility and calcification would favor PMV. Surgical therapy for mitral stenosis should be reserved, for patients who have $\leq 2+$ Sellers grade of MR by angiography, and for those patients with severe mitral valve 
thickening and calcification or with significant sub valvular scarring to warrant mitral valve replacement. Nowadays the evaluation and grading of mitral regurgitation is eminently echocardiographic. Although the distinction between mild and severe grade of mitral regurgitation using echocardiography is easy, it is not the same for the cases of intermediate (II and III) grades. Doppler echocardiography is dependent on hemodynamic parameters such as the preload, afterload, and rhythm, anatomic parameters such as the dimensions of left atrium, technical parameters such as the "window", and operator's experience. Thus, echocardiographic evaluation of mitral regurgitation severity should be done using an integrative approach that incorporates multiple parameters, including semi-quantitative measures (vena contracta width or area) and quantitative measures (effective regurgitant orifice area, regurgitant volume, and regurgitant fraction).

\section{DECLARATIONS}

\section{Authors' contributions}

The author contributed solely to the article.

\section{Availability of data and materials}

Not applicable.

\section{Financial support and sponsorship}

None.

\section{Conflicts of interest}

The author declared that there are no conflicts of interest.

\section{Ethical approval and consent to participate}

Not applicable.

\section{Consent for publication}

Not applicable.

\section{Copyright}

(c) The Author(s) 2020.

\section{REFERENCES}

1. Palacios IF. Percutaneous mitral balloon valvuloplasty for patients with rheumatic mitral stenosis. In: Herrmann HC, editor. Interventional cardiology: percutaneous noncoronary intervention. Totowa, NJ: Humana Press; 2005. pp. 3-27.

2. Palacios IF, Arzamendi D. Percutaneous mitral balloon valvuloplasty for patients with rheumatic mitral stenosis. Interv Cardiol Clin 2012;1:45-61.

3. Palacios IF. Percutaneous mitral balloon valvuloplasty: worldwide trends. J Am Heart Assoc 2019;8:e012898.

4. Inoue K, Owaki T, Nakamura T, Kitamura F, Miyamoto N. Clinical application of transvenous mitral commissurotomy by a new balloon catheter. J Thorac Cardiovasc Surg 1984;87:394-402.

5. Palacios I, Lock JE, Keane JF, Block PC. Percutaneous transvenous balloon valvotomy in a patient with severe calcific mitral stenosis. J Am Coll Cardiol 1986;7:1416-9.

6. Palacios I, Block PC, Brandi S, Blanco P, Casal H, et al. Percutaneous balloon valvotomy for patients with severe mitral stenosis. Circulation 1987;75:778-84.

7. Abascal VM, O’Shea JP, Wilkins GT, Palacios IF, Thomas JD, et al. Prediction of successful outcome in 130 patients undergoing percutaneous balloon mitral valvotomy. Circulation 1990;82:448-56.

8. Palacios IF, Block PC, Wilkins GT, Weyman AE. Follow-up of patients undergoing percutaneous mitral balloon valvotomy. Analysis of factors determining restenosis. Circulation 1989;79:573-9.

9. Dean LS, Mickel M, Bonan R, Holmes DR, O’Neil WW, et al. Four-year follow-up of patients undergoing percutaneous balloon mitral commissurotomy: a report from the National Heart, Lung, and Blood Institute Balloon Valvuloplasty Registry. J Am Coll Cardiol 1996;28:1452-7.

10. Palacios IF, Sanchez PL, Harrell LC, Weyman AE, Block PC. Which patients benefit from percutaneous mitral balloon valvuloplasty? Pre 
and post-valvuloplasty variables that predict 15-year outcome. Circulation 2002;105:1465-71.

11. Chen CR, Cheng TO, Chen JY, Huang YG, Huang T, et al. Long-term results of percutaneous balloon mitral valvuloplasty for mitral stenosis: a follow-up study to 11 years in 202 patients. Cathet Cardiovasc Diagn 1998;43:132-9.

12. Wilkins GT, Weyman AE, Abascal VM, Block PC, Palacios IF. Percutaneous mitral valvotomy: an analysis of echocardiographic variables related to outcome and the mechanism of dilatation. Br Heart J 1988;60:299-308.

13. Nishimura RA, Otto CM, Bonow RO, Carabello BA, Erwin JP 3rd, et al. 2017/ACC Focused Update of the 2014 AHA/ACC Guideline for the Management of Patients With Valvular Heart Disease: A Report of the American College of Cardiology/American Heart Association Task Force on Clinical Practice Guidelines. Circulation 2017;135:e1159-95.

14. Baumgartner H, Falk V, Bax JJ, De Bonis M, Hamm C, et al. 2017 ESC/EACTS Guidelines for the management of valvular heart disease. Kardiol Pol 2017;38:2739-91.

15. Mc Kay CR, Kawanishi DT, Rahimtoola SH. Catheter balloon valvuloplasty of the mitral valve in adults using a double balloon technique: early hemodynamic results. JAMA 1987;257:1753-61.

16. Vahanian A, Michel PL, Cormier B, Vitoux B, Michel X, et al. Results of percutaneous mitral commissurotomy in 200 patients. Am J Cardiol 1989;63:847-52.

17. Hernandez R, Banuelos C, Alfonso F, Goicolea J, Fernández-Ortiz A, et al. Long-term clinical and echocardiographic follow-up after percutaneous mitral valvuloplasty with the Inoue balloon. Circulation 1999;99:1580-6.

18. Herrmann HC, Ramaswamy K, Isner JM, Feldman TE, Carroll JD, et al. Factors influencing immediate results, complications and shortterm follow-up status after Inoue balloon mitral valvotomy: a North American multicenter study. Am Heart J 1992;124:160-6.

19. Arora R, Nair M, Kalra GS, Nigam M, Khalilu Uah M. Immediate and long-term results of balloon and surgical closed mitral valvotomy: a randomized comparative study. Am Heart J 1993;125:1091-4.

20. Tuzcu EM, Block PC, Newell JB, Palacios IF. Immediate and long-term outcome of percutaneous mitral valvotomy in patients 65 years and older. Circulation 1992;85:963-71.

21. Cruz-Gonzalez I, Sanchez-Ledesma M, Sanchez PL, Martin-Moreiras J, Jneid H, et al. Predicting success and long-term outcomes of percutaneous mitral valvuloplasty: a multifactorial score. Am J Med 2009;122:581.

22. Lung B, Garbarz E, Michaud P, Helou S, Farah B, et al. Late results of percutaneous mitral commissurotomy in a series of 1024 patients: analysis of late clinical deterioration: frequency, anatomic findings and predictive factors. Circulation 1999;99:3272-8

23. Nunes MCP, Tan TC, Elmariah S, Do Lago R, Margey R, et al. Echo score revisited impact of incorporating commissural morphology and leaflet displacement to the prediction of outcome for patients undergoing percutaneous mitral valvuloplasty. Circulation 2014;129:886-95.

24. Sanchez PL, Rodriguez-Alemparte M, Inglessis I, Palacios IF. The impact of age in the immediate and long-term outcomes of percutaneous mitral balloon valvuloplasty. J Interv Cardiol 2005;18:217-25.

25. Padial LR, Freitas N, Sagie A, Newell JB, Weyman AE, et al. Echocardiography can predict which patients will develop severe mitral regurgitation following percutaneous mitral valvulotomy. J Am Coll Cardiol 1996;27:1225-31.

26. Padial LR, Abascal VM, Moreno PR, Weyman AE, Levine RA, et al. Echocardiography can predict the development of severe mitral regurgitation after percutaneous mitral valvuloplasty by the Inoue technique. Am J Cardiol 1999;83:1210-3.

27. Rodrigues L, Monterroso VH, Abascal VM, King ME, O'Shea JP, et al. Does asymmetric mitral valve disease predict an adverse outcome after percutaneous balloon mitral valvotomy? An echocardiographic study. Am Heart Jnl 1992;123:1678-82.

28. Anwar AM, Attia WM, Nosir YFM, Osama I, Soliman I, et al. Validation of a new score for the assessment of mitral stenosis using realtime three-dimensional echocardiography. J Am Soc Echocardiogr 2010;23:13-22.

29. Abascal VM, Moreno PR, Rodriguez L, Monterroso VM, Palacios IF, et al. Comparison of the usefulness of Doppler pressure half-time in mitral stenosis in patients $<65$ and $\geq 65$ years of age. Am J Cardiol 1996;78:1390-3.

30. Palacios IF, Tuzcu ME, Weyman A, Newell JB, Block PC. Clinical follow-up of patients undergoing percutaneous mitral balloon valvotomy. Circulation 1995;91:671-6.

31. Cannan CR, Nishimura RA, Reeder GS, Ilstrup DR, Larson DR, et al. Echocardiographic assessment of commissural calcium: a simple predictor of outcome after percutaneous mitral balloon valvotomy. J Am Coll Cardiol 1996;29:175-80.

32. Maisano F. Expanding the indications for percutaneous mitral commissurotomy in rheumatic mitral stenosis: look carefully at the commissures and proceed cautiously and skillfully. Eur Heart J 2014;35:1575-7.

33. Babic UU, Dorros G, Pejcic P, Djurisic Z, Vucinic M, et al. Percutaneous mitral valvuloplasty: retrograde, transarterial double-balloon technique utilizing the transseptal approach. Cathet Cardiovasc Diagn 1988;14:229-437.

34. Stefanadis C, Kouroklis C, Stratos C, Pitsavos C, Tentolouris C, et al. Percutaneous balloon mitral valvuloplasty by retrograde left atrial catheterization. Am J Cardiol 1990;65:650-4.

35. Stefanadis C, Stratos C, Pitsavos C, Kallikazaros I, Triposkiadis F, et al. Retrograde non-transseptal balloon mitral valvuloplasty. Immediate results and long-term follow-up. Circulation 1992;85:1760-7.

36. Farman MT, Khan N, Sial JA, Saghir T, Ashraf T, et al. Predictors of successful percutaneous transvenous mitral commissurotomy using the bonhoeffer multi-track system in patients with moderate to severe mitral stenosis: can we see beyond the wilkins score? Anatol J Cardiol 2015; 15:37379.

37. Feldman T, Carroll JD, Herrmann HC, Holmes DR, Bashore TM, et al. Effect of balloon size and stepwise inflation technique on the acute results of Inoue mitral commissurotomy. Cathet Cardiovasc Diagn 1993;28:199-205.

38. Cribier A, Eltchaninoff H, Koning R, Rath PC, Arora R, et al. Percutaneous mechanical mitral commissurotomy with a newly designed metallic valvulotome: immediate results of the initial experience in 153 patients. Circulation 1999;99:793-9.

39. Cribier A, Eltchaninoff H, Carlot R, Bizet C, Giron C, et al. Percutaneous mechanical mitral commissurotomy with the metallic 
valvulotome: detailed technical aspects and overview of the results of the multicenter registry in 882 patients. J Interv Cardiol 2000;13:255-62.

40. Roelke M, Smith AJ, Palacios IF. The technique and safety of transseptal left heart catheterization: the Massachusetts General Hospital experience with 1,279 procedures. Cathet Cardiovasc Diagn 1994;32:332-9.

41. Sakata Y, Feldman T. Transcatheter creation of atrial septal perforation using a radiofrequency transseptal system: novel approach as an alternative to transseptal needle puncture. Catheter Cardiovasc Interv 2005;64:327-32.

42. Abascal VM, Chen C, Palacios IF. Echocardiography in percutaneous balloon mitral valvuloplasty. Echocardiography 1997;14:481-95.

43. Block PC, Palacios IF, Block EH, Tuzcu EM, Griffin B. Late (two-year) follow-up after percutaneous balloon mitral valvotomy. Am J Cardiol 1992;69:537-41.

44. O'Shea JP, Abascal VM, Wilkins GT, Marshall JE, Brandi S, et al. Unusual sequelae after percutaneous mitral valvuloplasty: a Dopplerechocardiographic study. J Am Coll Cardiol 1992;19:186-91.

45. Casale P, Block PC, O'Shea JP, Palacios IF. Atrial septal defect after percutaneous mitral balloon valvuloplasty: Immediate results and follow-up. J Am Coll Cardiol 1990;15:1300-4.

46. Sellers Rd, Levy MJ, Amplatz K, Lillehei CW. Left retrograde cardioangiography in acquired cardiac disease. Am J Cardiol 1964;14:437-47.

47. Turi ZG, Reyes VP, Raju BS, Raju AR, Kumar DN, et al. Percutaneous balloon versus surgical closed commissurotomy for mitral stenosis: a prospective, randomized trial. Circulation 1991;83:1179-85.

48. Jang IK, Block PC, Newell JB, Tuzcu EM, Palacios IF. Percutaneous mitral balloon valvotomy for recurrent mitral stenosis after surgical commissurotomy. Am J Cardiol 1995;75:601-5.

49. Pathan AZ, Mahdi NA, Leon MN, Lopez-Cuellar J, Simosa H, et al. Is redo percutaneous mitral balloon valvuloplasty (PMV) indicated in patients with post-PMV mitral restenosis? J Am Coll Cardiol 1999;34:49-54.

50. Farhat MB, Ayari M, Maatouk F, Betbout F, Gamra H, et al. Percutaneous balloon versus surgical closed and open commissurotomy: seven-year follow-up results of a randomized trial. Circulation 1998;97:245-50.

51. Palacios IF, Block PC, Wilkins GT, Rediker DE, Daggett WM. Percutaneous mitral balloon valvotomy during pregnancy in patients with severe mitral stenosis. Cathet Cardiovasc Diagn 1988;15:109-11.

52. Esteves CA, Munoz JS, Braga S, Andrade J, Meneghelo Z, et al. Immediate and long-term follow-up of percutaneous balloon mitral valvuloplasty in pregnant patients with rheumatic mitral stenosis. Am J Cardiol 2006;98:812-6.

53. Tuzcu EM, Block PC, Griffin BP, Newell JB, Palacios IF. Percutaneous mitral balloon valvotomy in patients with calcific mitral stenosis: immediate and long-term outcome. J Am Coll Cardiol 1994;23:1604-9.

54. Leon MN, Harrell LC, Simosa HF, Mahdi NA, Pathan A, et al. Mitral balloon valvotomy for patients with mitral stenosis in atrial fibrillation: Immediate and long-term results. J Am Coll Cardiol 1999;34:1145-52.

55. Palacios IF. Farewell to surgical mitral commissurotomy for many patients. Circulation 1998;97:223-6.

56. Sanchez-Ledesma M, Cruz-Gonzalez I, Sanchez PL, Martin-Moreiras J, Jneid H, et al. Impact of concomitant aortic regurgitation on percutaneous mitral valvuloplasty: Immediate results, short-term, and long-term outcome. Am Heart J 2008;156:361-6.

57. Leon MN, Harrell LC, Simosa HF, Mahdi NA, Pathan AZ, et al. Comparison of immediate and long-term results of mitral balloon valvotomy with the double balloon versus Inoue techniques. Am J Cardiol 1999;83:1356-63.

58. Sanchez PL, Harrell LC, Salas RE, Palacios IF. Learning curve of the Inoue technique of mitral balloon valvuloplasty. Am J Cardiol 2001;88:662-7.

59. Cruz-Gonzalez I, Semigram MJ, Inglessis-Azuaje I, Sanchez-Ledesma M, Martin-Moreiras J, et al. Effect of elevated pulmonary vascular resistance on outcomes after percutaneous mitral valvuloplasty. Am J Cardiol 2013;112:580-4.

60. Elmariah S, Arzamendi D, Llanos A, Margey RJ, Inglessis, et al. First experience with transcatheter valve-in- valve implantation for a stenotic mitral prosthesis within the United States. ACC Cardiovasc Interv 2012;5:e13-4.

61. Guerrero M, Urena M, Himbert D, Wang DD, Eleid M, et al. 1-year outcomes of transcatheter mitral valve replacement in patients with severe mitral annular calcification. J Am Coll Cardiol 2018;71:1841-53.

62. Hamatani Y, Saito N, Tazaki J, Natsuaki M, Nakai K, et al. Percutaneous balloon valvuloplasty for bioprosthetic mitral valve stenosis Heart Vessels 2013;28:667-71.

63. Lip GY, Wasfi M, Halim M, Singh H. Percutaneous balloon valvuloplasty of stenosed mitral bioprosthesis. Int J Cardiol 1997;59:97-100.

64. Orrange SE, Kawanishi DT, Lopez BM, Curry SM, Rahimtoola SH. Actuarial outcome after catheter balloon commissurotomy in patients with mitral stenosis. Circulation 1997;97:245-50.

65. Reyes VP, Raju BS, Wynne J, Stephenson LW, Raju R, et al. Percutaneous balloon valvuloplasty compared with open surgical commissurotomy for mitral stenosis. N Engl J Med 1994;331:961-7. 